\title{
(6) OPEN ACCESS \\ British Society of Gastroenterology position statement on serrated polyps in the colon and rectum
}

For numbered affiliations see end of article.

\section{Correspondence to}

Dr James E East, Translational Gastroenterology Unit

Experimental Medicine Division, Nuffield Department of Clinical Medicine, University of Oxford John Radcliffe Hospital, Headley Way, Headington, Oxford OX3 9DU, UK;

james.east@ndm.ox.ac.uk

Received 20 February 2017 Revised 31 March 2017 Accepted 3 April 2017 Published Online First 27 April 2017
CrossMark

To cite: East JE, Atkin WS, Bateman AC, et al. Gut 2017:66:1181-1196.

James E East, ${ }^{1}$ Wendy S Atkin, ${ }^{2}$ Adrian C Bateman, ${ }^{3}$ Susan K Clark, ${ }^{4}$ Sunil Dolwani, ${ }^{5}$ Shara N Ket, ${ }^{1}$ Simon J Leedham, ${ }^{6}$ Perminder S Phull, ${ }^{7}$ Matt D Rutter, ${ }^{8,9}$ Neil A Shepherd, ${ }^{10}$ Ian Tomlinson, ${ }^{11}$ Colin J Rees ${ }^{9,12}$

\section{ABSTRACT}

Serrated polyps have been recognised in the last decade as important premalignant lesions accounting for between $15 \%$ and $30 \%$ of colorectal cancers. There is therefore a clinical need for guidance on how to manage these lesions; however, the evidence base is limited. A working group was commission by the British Society of Gastroenterology (BSG) Endoscopy section to review the available evidence and develop a position statement to provide clinical guidance until the evidence becomes available to support a formal guideline. The scope of the position statement was wide-ranging and included: evidence that serrated lesions have premalignant potential; detection and resection of serrated lesions; surveillance strategies after detection of serrated lesions; special situations - serrated polyposis syndrome (including surgery) and serrated lesions in colitis; education, audit and benchmarks and research questions. Statements on these issues were proposed where the evidence was deemed sufficient, and reevaluated modified via a Delphi process until $>80 \%$ agreement was reached. The Grading of Recommendations, Assessment, Development and Evaluations (GRADE) tool was used to assess the strength of evidence and strength of recommendation for finalised statements. Key recommendation: we suggest that until further evidence on the efficacy or otherwise of surveillance are published, patients with sessile serrated lesions (SSLS) that appear associated with a higher risk of future neoplasia or colorectal cancer (SSLs $\geq 10 \mathrm{~mm}$ or serrated lesions harbouring dysplasia including traditional serrated adenomas) should be offered a one-off colonoscopic surveillance examination at 3 years (weak recommendation, low quality evidence, $90 \%$ agreement).

\section{SUMMARY OF RECOMMENDATIONS}

Evidence that serrated lesions (SLs) have premalignant potential

\section{Statement 1}

Some SSLs have molecular, genetic and pathological features consistent with being precursor lesions to CpG island methylator phenotype (CIMP)+ colorectal cancers (CRCs), which represent $15 \%-30 \%$ of all CRCs (moderate quality evidence, $100 \%$ agreement).
Pathology and nomenclature of SLs

\section{Statement 2}

We suggest adopting the terms hyperplastic polyp (HP), SSL, SSL with dysplasia, traditional serrated adenoma (TSA) or mixed polyp to describe SLs in the colorectum, using the WHO criteria to define SSL (weak recommendation, low quality evidence, $82 \%$ agreement).

Detection and resection of SLs

\section{Statement 3}

We suggest a minimum withdrawal time of $6 \mathrm{~min}$ to enhance SL detection. Chromoendoscopy can also enhance SL detection (weak recommendation, low quality evidence, $100 \%$ agreement).

Statement 4

We recommend that colonoscopy is the best current test for SL detection, with other modalities performing less well (faecal occult blood test (FOBT)/faecal immunochemical test (FIT) \pm stool DNA, CT colonography (CTC), flexible sigmoidoscopy, capsule colonoscopy) (strong recommendation, moderate quality evidence, $100 \%$ agreement).

\section{Statement 5}

We suggest that endoscopic resection of proximal SSLs, particularly those $\geq 10 \mathrm{~mm}$ in size, should be undertaken by operators who demonstrate achievement of outcomes for incomplete resection rates, serrated polyp detection rates and expertise in assessment of these at colonoscopy (see BSG-Association of Coloproctology of Great Britain and Ireland (ACPGBI) guideline on large non-pedunculated colorectal polyps (LNPCPs) 2015 and statements 13 and 14) (weak recommendation, low quality evidence, $91 \%$ agreement).

Surveillance strategies after detection of SLs

\section{Statement 6}

We suggest that given the elevated CRC risk in patients who meet the WHO criteria for serrated polyposis syndrome (SPS), and that effective surveillance appears to reduce CRC risk, these patients should be offered one to two yearly colonoscopic surveillance (weak recommendation, low quality evidence, $90 \%$ agreement). 


\section{Statement 7}

We suggest that after piecemeal endoscopic mucosal resection (EMR) of a $\mathrm{SL} \geq 20 \mathrm{~mm}$ that an examination of the resection site be performed within 2-6 months postresection (weak recommendation, low quality evidence, $100 \%$ agreement). Statement 8

We suggest that until further evidence on the efficacy or otherwise of surveillance are published, patients with SSLs that appear associated with a higher risk of future neoplasia or CRC (SSLs $\geq 10 \mathrm{~mm}$ or SLs harbouring dysplasia including TSAs) should be offered a one-off colonoscopic surveillance examination at 3 years (weak recommendation, low quality evidence, $90 \%$ agreement).

\section{Statement 9}

We suggest that at present for HPs or SSLs $<10 \mathrm{~mm}$ in size without dysplasia, there is no clear indication for colonoscopic surveillance unless sufficient in size, location and number to meet the criteria for SPS (weak recommendation, very low quality evidence, $90 \%$ agreement).

\section{Special situations: SPS}

\section{Statement 10}

We suggest that upper GI surveillance for polyposis or extraluminal surveillance for non-GI cancers is not necessary in patients with SPS where other genetic causes have been excluded (weak recommendation, very low quality evidence, $100 \%$ agreement).

\section{Statement 11}

We suggest that all patients with SPS should be referred to clinical genetics services or a polyposis registry, where local resources allow (weak recommendation, very low quality evidence, $100 \%$ agreement).

\section{Statement 12}

We suggest that surgery should be considered in patients with SPS who have lesions that are not amenable to colonoscopic resection because of their size, site or number (weak recommendation, very low quality evidence, $100 \%$ agreeent). We suggest that surgery should aim to remove all lesions that are not amenable to endoscopic resection, and could take the form of: segmental colectomy, total colectomy with ileorectal anastomosis or proctocolectomy (with or without ileoanal pouch formation) depending on the lesion burden and distribution (weak recommendation, very low quality evidence, 100\% agreement).

\section{Education, audit and benchmarks and research questions}

\section{Statement 13}

We recommend that clinicians involved in the care of patients with serrated polyps, especially endoscopists and pathologists, acquire the knowledge and skills to recognise and differentiate the various types of SLs (strong recommendation, moderate quality evidence, $100 \%$ agreement).

\section{Statement 14}

We suggest that benchmarking SL detection rates is challenging and affected by case mix, patient ethnicity, histopathological diagnosis and the inclusion of distal SLs; however, endoscopists who wish to assess their proximal serrated polyp detection rate might aim for a detection rate $>5 \%$ (weak recommendation, low quality evidence, $88 \%$ agreement).

\section{Statement 15}

We suggest that the current evidence base for clinical decision making for patients with SLs is poor. Clinicians are strongly advised to support prospective studies that will bolster this evidence and avoid empirical management decisions, to allow formal guidelines to be developed (weak recommendation, low quality evidence, $100 \%$ agreement).

\section{BACKGROUND AND METHODOLOGY}

This British Society of Gastroenterology (BSG) position statement is the output of a working group convened by the vice presidents for the BSG (Endoscopy section) to provide clinical guidance on the management of patients diagnosed with hyperplastic and serrated polyps. Topics for the review were developed by the multidisciplinary working group including basic scientists (SJL, IT), clinical geneticists (IT), pathologists (ACB, NAS), gastroenterologists (JEE, SD, SNK, PSP, MDR, CJR), colorectal surgeons (SKC) and epidemiologists (WSA). These topics include major clinical issues encountered by clinicians caring for patients with hyperplastic and serrated polyps, as well as audit and benchmarks, education and questions for further research. As the evidence base was not felt to be sufficient for a formal BSG guideline, a position statement was developed, which offers clinical guidance and points the likely direction of thinking of the society, with the position statement being replaced by a formal guideline in due course.

An initial teleconference was used to outline key clinical questions for the group to consider. For each identified question, a member of the working group performed a comprehensive keyword literature search, reviewed and analysed the quality of the evidence and summarised the key points. Where appropriate evidence existed, a 'position statement' was drawn up according to the GRADE recommendations (strong or weak/conditional recommendations; high, moderate, low or very low quality evidence). ${ }^{1}$ Following each round of electronic voting, statements were adopted using a modified Delphi process when $\geq 80 \%$ of the working group agreed with them. If after two rounds there was continuing disagreement, if 50\% of the group agreed and $<20 \%$ disagreed, statements were accepted. ${ }^{2}$ Initial searches were completed in June 2015; during the Delphi process for non-agreed statements that required subsequent rounds, further searches for key papers that might further guide the working group were permitted due to initially poor but rapidly developing evidence base, final search June 2016. The position statement has been reviewed and agreed by the BSG Endoscopy Section Committee and BSG Clinical Standards and Services Committee.

This is not a BSG clinical guideline due to the methodology used; however, it does represent the view of the multidisciplinary expert working group panel, which represent BSG Endoscopy, Pathology and Colorectal sections. The group also includes representatives from NHS Bowel Cancer Screening Programme, Bowel Screening Wales, Scottish Bowel Cancer Screening and Welsh Association for Gastroenterology and Endoscopy, but does not imply endorsement from these groups.

\section{INTRODUCTION}

The adenoma-carcinoma sequence describes the sequential accumulation of a series of genetic mutations leading to advanced adenomas and then invasive cancer. ${ }^{3} 4$ Over the last 30 years, this model has been used as an essential framework to understand the pathogenesis of CRC. More recently, painstaking 
molecular and phenotypic characterisation of CRC has demonstrated significant pathogenic heterogeneity and the taxonomic subdivision of CRC now necessarily encompasses the tumour precursor lesion and molecular pathogenesis, alongside lesion distribution and morphological phenotype (figure 1).

Importantly, these alternative pathways to the conventional adenoma-carcinoma model appear to account for 15\%-30\% of CRC cases and are significantly over-represented in interval cancers (figure 1)..$^{5-7}$ Hyperplastic (serrated) polyps had previously been considered benign and lacking in premalignant potential ${ }^{8}$ however, multiple lines of evidence suggested that some subtypes of HP were precursor lesions for cancers of nonadenomatous origin, as part of the 'serrated pathway' to CRC. 910

\section{Evidence that SLs have premalignant potential}

Molecular, genetic, pathological and epidemiological

\section{CpG island methylator phenotype}

Methylation is the addition of a methyl group $\left(\mathrm{CH}_{3}\right)$ to the cytosine nucleotide in a $\mathrm{CpG}$ dinucleotide context. Methylation of gene promoters is a physiological mechanism to regulate gene expression without altering the DNA sequence and is thus termed an 'epigenetic' change. When aberrant DNA methylation results in the transcriptional silencing of important tumour suppressor genes, neoplastic growth can be promoted. This aberrant methylation has been called the CIMP and is thought to be important in the serrated pathway. CIMP status can be detected by screening a panel of genes that are known to be particularly susceptible to promoter methylation. ${ }^{10} \mathrm{CIMP}+$ tumours probably account for a third of all CRCs, ${ }^{9} 11$ although the prevalence varies considerably depending on the marker panel used, the population being studied and the colonic regional distribution. ${ }^{12}$

\section{The serrated neoplasia pathway}

SLs of the colorectum are characterised histologically by a sawtoothed appearance of the crypt epithelium. Formerly, all lesions exhibiting this characteristic morphology were called HPs and were thought to have no malignant potential; ${ }^{8}$ however, more recently SLs have been characterised by their morphological and molecular profiles into different subsets, which vary in their risk of malignant transformation.

\section{Sessile serrated lesions}

The use of CIMP marker panels provided molecular tools to investigate the precursor lesions of CIMP+ tumours. Many benign sessile serrated polyps (SSPs) are BRAF mutant and are CIMP $+{ }^{13-16}$ and analysis of SSLs with an adjacent region of cancer show shared immunohistochemical and molecular features between the benign and malignant foci. ${ }^{17-19}$ Furthermore, case reports describe the development of cancer within serrated polyps that were left in situ and followed-up endoscopically. ${ }^{20} 21$ This evidence has led to the establishment of a proposed serrated neoplasia pathway, where HPs initiated by BRAF or less commonly KRAS, mutation proceed to SSLs with the accumulation of epigenetic gene silencing, although it may be that SSLs arise de novo. Inactivation of tumour suppressor genes causes the development of cellular atypia (SSL with dysplasia) with eventual progression to cancer. There is a progressive increase of $B R A F$ mutant CIMP+ tumours from the rectum to the caecum $^{22}$ and the reason behind this proximal predilection is unknown.

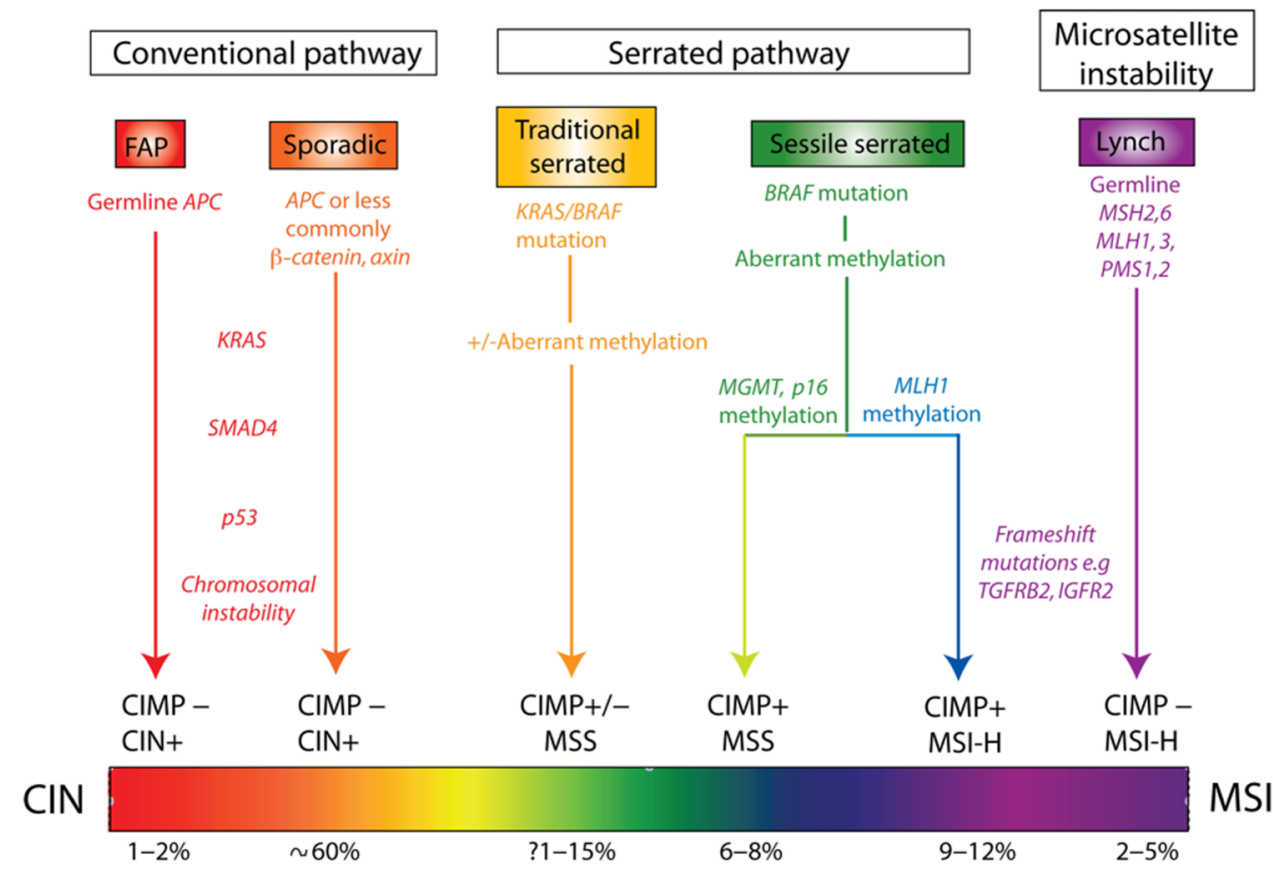

Figure 1 Considering the spectrum of colorectal cancer (CRC) — conventional adenomas progress by the sequential accumulation of genetic mutations and chromosomal instability causing microsatellite stable (MSS) tumours. Microsatellite instability (MSI) is the result of defective DNA repair through inactivation of mismatch repair genes and is epitomised by the germline mutation of Mis-Match Repair (MMR) genes seen in Lynch syndrome (hereditary non-polyposis coli). The sessile serrated neoplasia pathway is often initiated by genetic mutation of $B R A F$ or KRAS genes but then progresses by methylation of tumour suppressing genes (CpG island methylator phenotype (CIMP)). Both MSS and unstable tumours can result depending on the genes epigenetically silenced as the lesions progress. Comparatively, little is known about the traditional serrated pathway, but evidence is accumulating that this is a distinct molecular subtype. ${ }^{9}$ FAP, familial adenomatous polyposis. 
Traditional serrated adenomas

The pathogenesis of these sporadic lesions is less clear. The serrated phenotype differs from that seen in HP and SSPs, resulting from surface indentations associated with the characteristic ectopic crypt foci that develop orthogonally to the crypt axis. ${ }^{23}$ Molecular features are not as clearly defined as SSLs, but includes KRAS or BRAF mutations ${ }^{23} 24$ along with variable levels of CIMP positivity. Recently, high levels of GREM1 expression in the epithelium of these lesions have been reported, with the suggestion that they are the sporadic corollary of polyps in hereditary mixed polyposis syndrome. ${ }^{25}$ Unlike some SSLs, these tumours do not appear to progress through mismatch repair gene methylation and microsatellite instability (MSI). ${ }^{26} 27$

The over-representation of $\mathrm{MSI}^{28}$ and CIMP $+{ }^{29}$ tumours in interval cancers (tumours identified in between endoscopic screening examinations) has led to the suggestion that sessile serrated adenomas (SSA) can progress very rapidly. This may be partly true for SLs that develop a mutator phenotype with the loss of $M L H-1$ function but the over-representation in interval tumours is just as likely to be due to the well-described difficulty in endoscopic detection of these lesions. ${ }^{5} 30$

\section{Statement 1}

Some SSLs have molecular, genetic and pathological features consistent with being precursor lesions to CIMP+ CRCs, which represent $15 \%-30 \%$ of all CRCs (moderate quality evidence, $100 \%$ agreement).

\section{Box 1 Key histological features of sessile serrated}

\section{lesions (SSLs)}

- Irregular distribution of crypts

- Dilatation of crypt bases

- Serration present at crypt bases

- Branched crypts

- Horizontal extension of crypt bases*

- Dysmaturation of cryptst

- Herniation of crypts through muscularis mucosa

- WHO criteria - at least three crypts or at least two adjacent crypts must show one or more of these features to enable a diagnosis of SSLs ${ }^{31}$

- American Gastroenterology Association criteria-one crypt showing the characteristic features is sufficient for the diagnosis of SSLs ${ }^{26}$

*Involved crypts often have an ' $L$ ' or inverted ' $T$ ' shape. tDysmaturation is disordered cellular maturation within crypts and is evidenced by subtle nuclear enlargement, crowding, pseudostratification and mitotic activity together with the presence of a disorganised mixture of non-mucus containing epithelial cells and mature goblet cells within the deep aspects of crypts. In this context, assessment of proliferation index, for example, using MIB-1 may provide supporting evidence for a diagnosis of SSLs by highlighting epithelial cell proliferation within the superficial half of crypts. However, such immunohistochemistry, while sometimes helpful, does not reveal features that are alone diagnostic of SSLS.

\section{Box 2 Recommended terminology for (non-invasive)} serrated lesions of the colon and rectum opinion between the UK, European and the US pathologists regarding the optimal terminology and the pathological features required to make a diagnosis of an SL (box 1). We recommend usage of the WHO criteria to diagnose SSL. This means that three crypts-or two adjacent crypts—showing at least one of the features listed in box 1 are required to be present for a diagnosis of SSL. There is no strict 'ranking order' of these features in terms of their importance for the diagnosis and there is also no minimum number of these features that need to be present (apart from the minimum number of characteristic crypts).

In this position statement we have elected to use terminology developed by Bateman and Shepherd, which is approved by the Pathology sections of the BSG and NHS Bowel Cancer Screening Programme. In the USA, the term SSA was originally coined, which encompassed the morphology of these lesions and implied their premalignant nature; however, such lesions do not generally contain 'true' cytological dysplasia. ${ }^{32}$ WHO proposed the term sessile serrated adenoma/polyp (SSA/P); ${ }^{31}$ however, again this suggests cytological atypia and many lesions would not meet the pathological definition of being polypoid. Therefore, the UK terminology recommends the term SSL with or without dysplasia. This accounts for the pathology and morphology seen and critically distinguishes lesions, which harbour cytological dysplasia that are thought to be higher risk and on an accelerated pathway to carcinogenesis. The recommended terms for the UK pathological classification of serrated polyps are listed in box 2. The 'mixed polyp' category was retained for unusual cases, for example, those showing mixed features of SSL and TSA, or polyps thought to represent true 'collision tumours' comprising an adenoma and an HP; however, most polyps showing features of SSL together with
- Hyperplastic polyp

- Sessile serrated lesion (SSL)

- SSL with dysplasia

- Traditional serrated adenoma

- Mixed polyp

one or more areas of dysplasia are likely to represent SSLs in which dysplasia has arisen, rather than 'collision tumours'.

There are problems of interobserver variability with the pathological reporting of SLs that may in part stem from variations in terminology and diagnostic criteria mainly between HPs an SSLs; ${ }^{30}$ 33-35 however, this is likely to improve with uniformity of terminology and experience, with one study showing use of a reference article may improve reproducibility. ${ }^{36}$ TSA show classical cytological dysplasia and distinctive features (eosinophilic cytoplasm, ectopic crypts, pencillate nuclei), and are managed more like classical adenomas.

Readers are directed to the guidance document for a more detailed discussion of the pathological issues (http://jcp.bmj. com/content/68/8/585.full.pdf + html). ${ }^{37}$

\section{Statement 2}

We suggest adopting the terms HP, SSL, SSL with dysplasia, TSA or mixed polyp to describe SLs in the colorectum, using the WHO criteria to define SSL (weak recommendation, low quality evidence, $82 \%$ agreement). 


\section{DETECTION AND RESECTION OF SLS Detection at colonoscopy \\ Prevalence}

The prevalence of SLs, and especially SSLs is difficult to determine accurately. The results from the published literature are highly variable, due to inconsistent diagnostic criteria, inappropriate histological classification of different subtypes, variation in polyp detection rates among endoscopists, use of different endoscopic enhancing modalities and population selection criteria. A number of studies have demonstrated that review of polyps previously labelled as hyperplastic results in significant numbers being reclassified as serrated adenomas. ${ }^{30} \quad 38-40$ Furthermore, there is substantial interobserver variation even among GI pathologists in diagnosing SSLs. ${ }^{39}$ Despite these caveats, there is evidence suggesting that SSL detection is improving, ${ }^{41}$ presumably as a result of either increased recognition by endoscopists and/or pathologists (table 1).

The prevalence of SLs based on autopsy studies has been reported as between $13 \%$ and $35 \%,{ }^{42-45}$ with these lesions accounting for $27 \%-51 \%$ of all colorectal polyps. ${ }^{42} 43$ More recent pathology series have demonstrated that the most common SL encountered is the HP, accounting for 24\%-42\% of all resected colorectal polyps and $83 \%-96 \%$ of all SLs; SSLs represent $2 \%-4 \%$ of all polyps and $3 \%-11 \%$ of SLs. TSAs are much less common, generally accounting for $<1 \%$ of all polyps and $1 \%-7 \%$ of SLs. ${ }^{46-48}$

The distribution of SLs varies with the type: HPs and TSAs are usually found in the left colon, while SSLs occur more often in the proximal colon. ${ }^{46-49}$ The published literature on colonoscopic detection of SLs is summarised in table 1. The studies have mostly been retrospective and have varied in the patient population, details of the colonoscopy procedure and reporting of the results. Excluding those studies that have investigated patients with MutYH-associated polyposis (MAP) or SPS, the majority of the evidence relates to average-risk screening patients. Overall, SLs account for $11 \%-53 \%$ of all polyps detected at colonoscopy in screening populations, ${ }^{41} 50-57$ SSLs for $1 \%-13 \%{ }^{41} 505257$ and TSAs for $0.1 \%-1.9 \% .^{50} 52$ Spring et al reported SL prevalence results for an unselected population (ie, symptomatic as well as screening patients), with SLs overall accounting for $40 \%$ of all polyps, SSLs for $9 \%$ and TSAs for $<1 \%$. Many patients will have more than one serrated polyp present; Álavrez et al reported that the mean number of serrated polyps detected was 2 , with a range of 1-25.

\section{Endoscopic appearance of SLs}

Endoscopically, HPs tend to be diminutive $(<5 \mathrm{~mm})$, pale, sessile $^{45}$ and have a type II asteroid, stellate or papillary Kudo pit pattern when examined with chromoendoscopy or narrowband imaging. ${ }^{58}$ The endoscopic features of SSLs include sessile or flat morphology ${ }^{59}{ }^{60}$ with proximal SSLs more likely to be flat than distal lesions, ${ }^{61}$ a resemblance to prominent folds, ${ }^{60}$ pale colour, ${ }^{59}$ indistinct borders $^{62}$ and mucus capping. ${ }^{60}$ In $52 \%$ of SSLs, a rim of bubbles or debris is present that can help delineate the lesions and serve as an identification aid. ${ }^{60}$ Additional features on narrow band imaging (NBI) include a cloud-like surface, an irregular shape and dark spots inside the crypts. $^{62}$ SSLs typically have a type II-O or open Kudo pit pattern on a magnified view; several studies have reported this pit pattern has good sensitivity (84\%-97\%) and specificity (66\%-86\%) for identifying SSLs. ${ }^{62-64}$ TSAs tend to be protuberant and/or pedunculated, with a type IV (pinecone-like or fern-like) pit pattern. ${ }^{50}$ In a prospective study, Rondagh et $a l^{66}$ demonstrated the proximal serrated polyps (PSPs) were more likely to be sessile and less likely to be diminutive compared with distally located lesions.

\section{Colonoscopy for SL detection}

There have been few studies which have focussed directly on colonoscopic detection of SLs. Most data are drawn from studies where SLs were detected incidentally and adenomas were the primary end point, and many predate accurate pathological distinction of SLs. Hence, data are not as robust as for adenoma detection rates (ADRs). Furthermore, there is no clear correlation between SL detection rates and interval cancer, unlike that seen for ADRs. Interval cancers are over-represented in the serrated pathway and higher 'polyp' detection rates have been shown to be protective for right-sided CRCs. ${ }^{67}$ It is possible therefore that improvements in SL detection rates might have a greater impact on interval cancer rates than improvements in ADR, although ADR and SL detection show some correlation (see benchmarks). Summary data on interventions which may or may not improve SL detection are presented in table 2 .

\section{Withdrawal time}

In a Dutch screening cohort, longer withdrawal time had an OR of 1.12 for detection of SLs. ${ }^{69}$ Analysis of data from the New Hampshire colonoscopy registry reported an incidence rate ratio of 1.77 for each minute beyond $6 \mathrm{~min}$ withdrawal time to a maximum at 9 min. $^{70}$ In both cases, similar improvements were seen for ADRs.

\section{Chromoendoscopy}

Chromoendoscopy consistently improves adenomatous as well as non-adenomatous polyps detection rates, with the vast majority of the latter being SLs. A summary of four studies performed between 2002 and 2006, reported an increase in hyperplastic or non-adenomatous polyp detection from $23 \%$ to $45 \%$ overall, and from $9 \%$ to $16 \%$ in the proximal colon. ${ }^{5}$ More recent studies have confirmed this result and effect size in multicentre studies from Germany $(46.2 \%$ vs $29.5 \%$ SLs, rectum excluded) ${ }^{73}$ and the USA (high-definition colonoscopes; mean non-neoplastic lesions per patient 1.8 vs 1.0). ${ }^{72}$ All studies used indigocarmine dye as a surface contrast agent. The use of chromoendoscopy to increase yield of serrated polyps in the right colon is currently being trialled in an FOBT-positive screening population in Wales (Contrast Enhanced Colonoscopy (CONSCOP) study; ClinicalTrials.gov identifier: NCT01972451).

\section{High definition}

In a small single-centre cohort study, detection rates for proximal HPs and for large $(\geq 10 \mathrm{~mm})$ HPs were not different. ${ }^{80}$ In a Dutch screening cohort, use of high-definition colonoscopes did not improve PSP detection, multivariate ORs 1.07. ${ }^{69}$ High-definition compared with standard-definition colonoscopy provided only a marginal incremental yield in polyp detection rates of $3.8 \%$ (95\% CI $1 \%$ to $6.7 \%)$ in a meta-analysis suggesting that any benefit seen may be small. ${ }^{81}$

\section{Proximal colon retroflexion}

Proximal colon retroflexion showed a modest increase in proximal SL detection, although this gain might have been achieved with a repeated examination in the forward view. ${ }^{74}$ 
Table 1 Summary of colonoscopic studies evaluating prevalence and detection rates for serrated lesions

\begin{tabular}{|c|c|c|c|c|c|c|c|c|}
\hline Authors & Year & Country & Study type & $\mathbf{n}$ & Patient population & $\begin{array}{l}\text { Colonoscopy } \\
\text { type }\end{array}$ & $\begin{array}{l}\text { Results } \\
\text { Prevalence }\end{array}$ & $\begin{array}{l}\text { Results } \\
\text { Detection rate }\end{array}$ \\
\hline Spring & 2006 & Australia & Prospective & 190 & All (except FAP, HNPCC, HPS) & $\mathrm{M}, \mathrm{CE}$ & $\begin{array}{l}\text { SL } 40 \% \\
\text { HP } 29 \% \\
\text { SSA } 9 \% \\
\text { TSA } 0.7 \%\end{array}$ & \\
\hline Hetzel & 2010 & USA & Retrospective & 7192 & Average-risk screening & HD & $\begin{array}{l}\text { HP } 28 \% \\
\text { SSA } 1.4 \%\end{array}$ & SSA-DR $0.6 \%$ \\
\hline Gurudu & 2010 & USA & Retrospective & 21238 & All & WL & & SSA-DR $2.9 \%$ \\
\hline Freedman & 2011 & USA & Retrospective & 1486 & $\begin{array}{l}\text { Average-risk screening (>45 years) or } \\
\text { surveillance }\end{array}$ & WL & SSP $6.9 \%$ & $\begin{array}{l}\text { HP-DR } 26 \% \\
\text { SSP-DR } 8 \%\end{array}$ \\
\hline Kahi & 2011 & USA & Retrospective & 6681 & Average-risk screening & WL & $\begin{array}{l}\text { SL } 36 \% \\
\text { PSP } 11 \%\end{array}$ & PSP-DR 13\% \\
\hline Rondagh & 2011 & $\begin{array}{l}\text { The } \\
\text { Netherlands }\end{array}$ & Prospective & 2309 & All (except any hereditary form of CRC, SPS) & $\mathrm{HD}, \mathrm{CE}$ & & $\begin{array}{l}\text { SL-DR } 13.3 \% \\
\text { High-risk SP*-DR } \\
2.5 \% \\
\text { PSP-DR } 3.8 \%\end{array}$ \\
\hline Buda & 2012 & Italy & Prospective & 985 & Average-risk screening & $\mathrm{HD}$ & $\begin{array}{l}\text { SP } 40 \% \\
\text { HP } 26.4 \% \\
\text { SSL } 10.9 \% \\
\text { TSA } 2.3 \%\end{array}$ & $\begin{array}{l}\text { SL-DR } 7.3 \% \\
\text { HP-DR } 4.5 \% \\
\text { SSL-DR } 2.3 \% \\
\text { TSA-DR } 0.5 \%\end{array}$ \\
\hline Leung & 2012 & $\begin{array}{l}\text { China (Hong } \\
\text { Kong) }\end{array}$ & Retrospective & 1282 & Average-risk screening & $\mathrm{HD}, \mathrm{NBI}$ & & $\begin{array}{l}\text { SP-DR } 21.4 \% \\
\text { SA-DR } 0.9 \% \\
\text { PSP-DR } 7.2 \% \\
\text { LSP-DR } 2.3 \%\end{array}$ \\
\hline Liang & 2012 & USA & Retrospective & 18003 & All & $\begin{array}{l}\text { Assumed WL (no } \\
\text { details) }\end{array}$ & & $\begin{array}{l}\text { SL-DR } 20.6 \% \\
\text { (screening only } \\
\text { SL-DR } 13.9 \% \text { ) }\end{array}$ \\
\hline Min & 2012 & South Korea & Retrospective & 926 & Average-risk screening ( $>45$ years) & WL & SP $17.5 \%$ & $\begin{array}{l}\text { SL-DR } 11.9 \% \\
\text { PSP-DR } 5.3 \%\end{array}$ \\
\hline Alvarez & 2013 & Spain & Prospective & 5059 & Average-risk screening (50-69 years) & $\begin{array}{l}\text { Assumed WL (no } \\
\text { details) }\end{array}$ & & $\begin{array}{l}\text { SL-DR 20.8\% } \\
\text { PSP-DR } 6.5 \% \\
\text { LSP-DR 1.8\% } \\
\text { SSA+TSA-DR 2.6\% }\end{array}$ \\
\hline Anderson & 2013 & USA & Retrospective & 9100 & $\begin{array}{l}\text { Average-risk screening and surveillance (all } \\
>50 \text { years, NB poor prep and incomplete } \\
\text { colonoscopy excluded) }\end{array}$ & $\begin{array}{l}\text { Assumed WL (no } \\
\text { details) }\end{array}$ & & $\begin{array}{l}\text { SL-DR† } 8 \% \\
\text { screening } \\
\text { SL-DR† 10\% } \\
\text { surveillance }\end{array}$ \\
\hline Kumbhari & 2013 & Australia & Retrospective & 1000 & All & WL, NBI & & $\begin{array}{l}\text { SSA-DR } 5.3 \% \\
\text { ( } 7 \% \text { in Caucasians } \\
\text { vs } 2 \% \text { in Chinese) }\end{array}$ \\
\hline Lee & 2013 & South Korea & Retrospective & 1375 & Average-risk screening ( $>50$ years) & $\mathrm{HD}$ & $\begin{array}{l}\text { SL } 11 \% \\
\text { PSP } 2.7 \%\end{array}$ & $\begin{array}{l}\text { SL-DR } 11.3 \% \\
\text { PSP-DR } 3.1 \% \\
\text { High-risk PSP-DR } \neq \\
0.5 \%\end{array}$ \\
\hline Raju & 2013 & USA & Retrospective & 342 & Average-risk screening (50-75 years) & WL§ & SL $11.3 \%$ & $\begin{array}{l}\text { SL-DR } 23 \% \\
\text { SSA+TSA-DR } 11 \%\end{array}$ \\
\hline Hazewinkel & 2014 & $\begin{array}{l}\text { The } \\
\text { Netherlands }\end{array}$ & Prospective & 1426 & Average-risk screening (50-75 years) & WL & $\begin{array}{l}\text { SL } 41.8 \% \\
\text { HP } 35.5 \% \\
\text { SSA } 6.2 \% \\
\text { TSA }<0.1 \%\end{array}$ & $\begin{array}{l}\text { SL-DR } 27.2 \% \\
\text { HP-DR } 23.8 \\
\text { PSP-DR } 12.2 \% \\
\text { SSA-DR } 4.8 \% \\
\text { TSA-DR } 0.1 \%\end{array}$ \\
\hline Payne & 2014 & $\begin{array}{l}\text { USA and } \\
\text { Germany }\end{array}$ & Retrospective & 7215 & Average-risk screening ( $>50$ years) & $\begin{array}{l}\text { Assumed WL (no } \\
\text { details) }\end{array}$ & SLๆ $6.1 \%$ & $\begin{array}{l}\text { SL-DR } 4 \% \\
\text { PSL-DR } 2.8 \%\end{array}$ \\
\hline
\end{tabular}

*Dysplastic serrated polyps or large ( $\geq 6 \mathrm{~mm})$ proximal non-dysplastic serrated polyps.

tHPs proximal to sigmoid colon plus all SSPs serrated adenomas.

$\ddagger$ Dysplastic PSP or large $(<1 \mathrm{~cm})$.

§Plus lesion-recognition training, cap-fitted colonoscopy, rigorous cleansing and intensive inspection.

TSSA/P or HPs $>1 \mathrm{~cm}$ in proximal colon.

CE, chromoendoscopy; CRC, colorectal cancer; FAP, familial adenomatous polyposis; HD, high definition; HNPCC, hereditary non-polyposis colorectal cancer; HP, hyperplastic polyp; LSP, large ( $>1 \mathrm{~cm}$ ) serrated polyp; M, magnification; NBI, narrow band imaging; PSP, proximal serrated polyp; S/HPS, serrated/hyperplastic polyposis syndrome; SA, serrated adenoma; SP, serrated polyp; SPS, serrated polyposis syndrome; SSA, sessile serrated adenoma; SSL, sessile serrated lesion; SSP, sessile serrated polyp; TSA, traditional serrated adenoma; WL, standard white light.

Narrowed spectrum endoscopy

NBI showed improved detection in a single-centre, singleoperator study for detection of SLs in the setting of SPS; ${ }^{82}$ however, a multicentre study from the same group did not confirm this. ${ }^{83}$ Four different meta-analyses of NBI versus white light, including more than 3000 patients, failed to show improvements in adenoma or polyp detection rates, suggesting a benefit for serrated polyps is unlikely. ${ }^{71}$ Similarly, there is no 
Table 2 Interventions at colonoscopy which may improve serrated lesion detection rates (adapted from East et $a{ }^{68}$ )

\begin{tabular}{|c|c|c|}
\hline Beneficial & $\begin{array}{l}\text { May be } \\
\text { beneficial }\end{array}$ & No clear benefit \\
\hline $\begin{array}{l}\text { Slower withdrawal } \\
>6 \min ^{69} 70\end{array}$ & High definition ${ }^{69}$ & $\begin{array}{l}\text { Narrowed spectrum endoscopy } \\
\text { (NBI, FICE, iSCAN) }^{71}\end{array}$ \\
\hline \multirow[t]{3}{*}{ Chromoendoscopy 7273} & $\begin{array}{l}\text { Right colon } \\
\text { retroflexion }^{74}\end{array}$ & Antispasmodics $^{75}$ \\
\hline & & $\begin{array}{l}\text { Good vs adequate bowel } \\
\text { preparation } 6976\end{array}$ \\
\hline & & $\begin{array}{l}\text { Wide angle and enhanced } \\
\text { mucosal views }\end{array}$ \\
\hline
\end{tabular}

clear detection benefit for either flexible spectral imaging colour enhancement (Fujinon) ${ }^{84-86}$ or iSCAN (Pentax) with tone enhancement. ${ }^{87-89}$

Recent data from the new generation of brighter NBI systems (Excera III, Olympus) in a large study looking specifically at SLs detection rates in the proximal colon did not show an overall benefit in the number of proximal SLs detected, but did show a significant benefit for larger SLs. ${ }^{90}$ Underwater endoscopy has been proposed to improve ADRs. Data for SL are limited but in one study combining two randomised controlled trials there was no overall benefit in proximal SL detection rate of $6 \%$ vs $12 \% .^{91}$

\section{Antispasmodics}

Hyoscine butylbromide (Buscopan) increased polyp detection in the right colon, 0.43 vs $0.31, p=0.01$ in one randomised controlled trial; ${ }^{92}$ however, a meta-analysis that included this study found no increase in polyp detection rate overall (OR 1.09, 95\% CI 0.91 to 1.31$).^{75}$

\section{Bowel preparation}

Few studies have had detection of SLs as a primary outcome. In a Dutch screening study, quality of bowel preparation was not associated with lower proximal SL detection rates, multivariate OR 0.98 (95\% CI 0.92 to 1.05$).{ }^{69}$ In a US registry-based study, serrated polyp detection rates were similar for optimal (excellent or good) versus fair bowel preparation, with an OR of 0.75 (95\% CI 0.31 to 1.80 ) for poor prep versus optimal prep for PSP detection. ${ }^{76}$ This effect may result from a thicker mucus cap on SLs with lower preparation quality assisting detection.

\section{Wide angle and enhanced mucosal views}

In a tandem study, the Third Eye Retroscope detected 77 vs 58 non-adenomatous polyps, but in the right colon this was only 19 vs 22 non-adenomatous polyps, so better detection of clinically relevant SLs was not demonstrated. ${ }^{77}$ Other novel devices to reveal more mucosa have been recently reported such as G-Eye, Full Spectrum Endoscopy and Third Eye Panoramic Device; ${ }^{78} 79$ however, no current studies report data that allow assessment of proximal SL detection rates. Data for SLs are not yet reported for SL detection rates for other devices, which may improve mucosal visualisation, for example, Endocuff, Endorings.

\section{Statement 3}

We suggest a minimum withdrawal time of 6 min to enhance SL detection. Chromoendoscopy can also enhance SL detection (weak recommendation, low quality evidence, 100\% agreement).

\section{Detection by other modalities}

Although colonoscopic detection of SLs may not be perfect, at present there is not enough evidence to suggest that colonoscopy can be replaced by alternative technologies. CTC has difficulty detecting flat and sessile lesions. The limited published data on the detection of lesions other than conventional adenomas by CTC suggest that this technique lacks adequate sensitivity. ${ }^{93}$ However, one recent study of flat colonic lesions has suggested that serrated and HPs are more likely to coat with oral contrast than adenomatous polyps, and this may represent a way forward in CTC identification of SLs. ${ }^{94}$

\section{Stool markers}

The potential role of FIT in detecting SLs has been evaluated in a recent study by Heigh et al; however, the results were poor at both 50 and $100 \mathrm{ng} / \mathrm{mL}$ cut-off values. This is probably because SLs are less likely to bleed than conventional adenomas. ${ }^{95}$

Stool DNA tests may offer the ability to detect SLs noninvasively. In a prospective study of 456 screening/surveillance patients, Heigh et al ${ }^{96}$ demonstrated that $m B M P 3$ proved highly discriminant for detection of SSLs $>1 \mathrm{~cm}$ in size. Lidgard et $a l^{97}$ evaluated the clinical performance of an automated stool DNA assay in a blinded, case-control study. Stool samples were analysed from 459 screening/surveillance patients and from 544 symptomatic patients, including 30 patients with SSAs. The stool DNA assay measured $\beta$-actin (a marker of total human DNA), mutant KRAS, aberrantly methylated BMP3 and NDRG4 and faecal haemoglobin. Its sensitivity for SSA $>1 \mathrm{~cm}$ was $60 \%$.

In a recent large study in an average-risk cohort by Imperiale et $a l^{98}$ using FIT versus FIT plus multitarget stool DNA testing, FIT plus DNA significantly outperformed FIT alone for the detection of serrated polyps $1 \mathrm{~cm}$ or more in size, $42.4 \%$ vs $5.1 \%$, respectively, $\mathrm{p}<0.001$.

Colon capsule data are limited, especially for reporting of serrated polyps; however, in the largest study reported the serrated polyp detection rate by capsule colonoscopy was up to a third less than by colonoscopy. ${ }^{99}$

\section{Statement 4}

We recommend that colonoscopy is the best current test for SL detection, with other modalities performing less well (FOBT/FIT \pm stool DNA, CTC, flexible sigmoidoscopy, capsule colonoscopy) (strong recommendation, moderate quality evidence, 100\% agreement).

\section{Resection}

There has been concern in the gastroenterological community that the risk of trying to resect SLs might potentially outweigh the reduction on CRC risk, especially for larger lesions in the 
right colon, ${ }^{100}$ mainly on the basis of data from a large German study of postpolypectomy complications pre-2005. ${ }^{101}$ For smaller SLs $<10 \mathrm{~mm}$ in size standard polypectomy techniques can be applied, although the flat morphology of the lesions can make them difficult to grip. Use of a stiff snare and submucosal lifting may help in these situations. For lesions in the proximal colon cold snaring is preferred.

We suggest that resection of large proximal SSPs is optimally dealt with by individuals and centres with expertise in recognition, detailed assessment and therapy of these lesions. This recommendation is based on the higher risk of incomplete resection and complications associated with removal of large sessile polyps in the right colon and some evidence of a favourable effect of a threshold volume for better outcomes. ${ }^{102-104}$ These data, combined with variability in SL detection and assessment (see statements 13 and 14), and data on comparing the similar outcomes on safety of endoscopic resection in adenomas and SSLs, ${ }^{105}$ suggest a significant role for operator variability and outcomes in the management of these lesions. Therefore, for larger lesions $\geq 10 \mathrm{~mm}$ endoscopists should meet the competencies and standards set out in the BSG 2015 guidelines on management of large non-polypoid colorectal polyps. ${ }^{104}$

Specific variations in technique such as underwater EMR, ${ }^{106}$ use of suction to create pseudopolyps ${ }^{107}$ and use of specific snares have been proposed as being of help but cannot be recommended at present as being significantly better than standard EMR technique to remove these lesions. ${ }^{108}$ There is some evidence to suggest that use of a microprocessor controlled diathermy unit, care with use of excessive diathermy and achieving complete endoscopic resection in the first attempt may help to reduce the incidence of complications and recurrence of these lesions. ${ }^{109} 110$

\section{Statement 5}

We suggest that endoscopic resection of proximal SSLS, particularly those $\geq 10 \mathrm{~mm}$ in size, should be undertaken by operators who demonstrate achievement of outcomes for incomplete resection rates, serrated polyp detection rates and expertise in assessment of these at colonoscopy (see BSGACPGBI guideline on LNPCPs 2015, and statements 13 and 14) (weak recommendation, low quality evidence, 91\% agreement).

\section{SURVEILLANCE STRATEGIES AFTER DETECTION OF SLS}

Data to guide surveillance strategy after detection of SLs are limited with essentially no high-quality prospective data available or likely to be available in the next few years.

\section{High-risk situations}

SPS (see the 'Serrated polyposis syndrome' section) appears to lead to a substantial future risk of CRC that can be reduced, at least over 5 years, by intensive colonoscopic surveillance. The US multisociety taskforce guidelines have suggested surveillance at one yearly intervals may be appropriate, ${ }^{111}$ although data on the effectiveness of yearly surveillance and possibly lower risks estimates of future cancer during surveillance were not available to these guidelines groups (see the 'Serrated polyps in colitis' section). Risk estimates do not seem to exceed those for Lynch syndrome and molecular mechanisms to CRC such as loss of DNA mismatch repair may be shared. Therefore, once all larger polyp have been removed, with only polyps $5 \mathrm{~mm}$ or less remaining, surveillance can be initiated every 1-2 years (see figure 2), with the later interval appropriate for those not developing further polyps rapidly once the colon has been cleared, see Hassan et $a l^{112}$ for suggested algorithm flow chart. Patients who are first-degree relatives of patients with SPS with at last one PSP (WHO criteria 2), but not meeting the WHO criteria 1 or 3 (see box 3 ) may be at lower risk. ${ }^{113}$

\section{Statement 6}

We suggest that given the elevated CRC risk in patients who meet the WHO criteria for SPS, and that effective surveillance appears to reduce CRC risk, these patients should be offered one to two yearly colonoscopic surveillance (weak recommendation, low quality evidence, $90 \%$ agreement).

There are data from clinical studies in adenomatous polyps that piecemeal resection increases the risk of lesion recurrence, ${ }^{114}$ with epidemiological data pointing to a risk of interval cancer from partly resected SLs. The CARE study suggested that rates of residual lesion are much higher for SLs than for adenomas. ${ }^{103}$ Therefore, it is logical that the same guidance after piecemeal resection of adenomas should apply to piecemeal resection of serrated polyps, that is, a site check at 2-6 months for lesions $20 \mathrm{~mm}$ or greater in size. This is consistent with the BSG 2015 guideline on management of large LNPCPs. ${ }^{104}$ This guideline also suggests that where possible polyps $<20 \mathrm{~mm}$ in size be resected en bloc; however, this may be a particular challenge for SL in the right colon. Therefore, if SLs between 10 and $20 \mathrm{~mm}$ are resected piecemeal it may be left to the endoscopist discretion as to whether a site check is required at 26 months or whether standard surveillance intervals can be applied (see statement 8), depending on patient factors and assessment of likelihood of complete excision. Recent data from a large series in Australia suggest that the recurrence rate for SSPs $\geq 20 \mathrm{~mm}$ resected with piecemeal EMR is lower than for adenomas but still significant, $7 \%$ vs $20 \%$ at 12 months. ${ }^{105}$

\section{Statement 7}

We suggest that after piecemeal EMR of a SL $\geq 20 \mathrm{~mm}$ that an examination of the resection site be performed within 2-6 months postresection (weak recommendation, low quality evidence, $100 \%$ agreement).

\section{Moderate risk situations}

The presence of sporadic SSA/Ps may represent an mucosal field defect with detection of one SSA/P making detection of synchronous $\mathrm{SSA} / \mathrm{P}^{115-117}$ as well as metachronous SSA/P during

\section{Box 3 WHO definition of serrated polyposis syndrome} $2010^{31 *}$

1. At least five serrated polyps proximal to the sigmoid colon, two of which are $>10 \mathrm{~mm}$ in diameter

2. Any number of serrated polyps occurring proximal to the sigmoid colon in an individual who has a first-degree relative with serrated polyposis

3. More than 20 serrated polyps of any size distributed throughout the colon

* Serrated lesion refers to any combination of hyperplastic polyps and sessile serrated polyps. 


\section{Serrated surveillance flowchart}

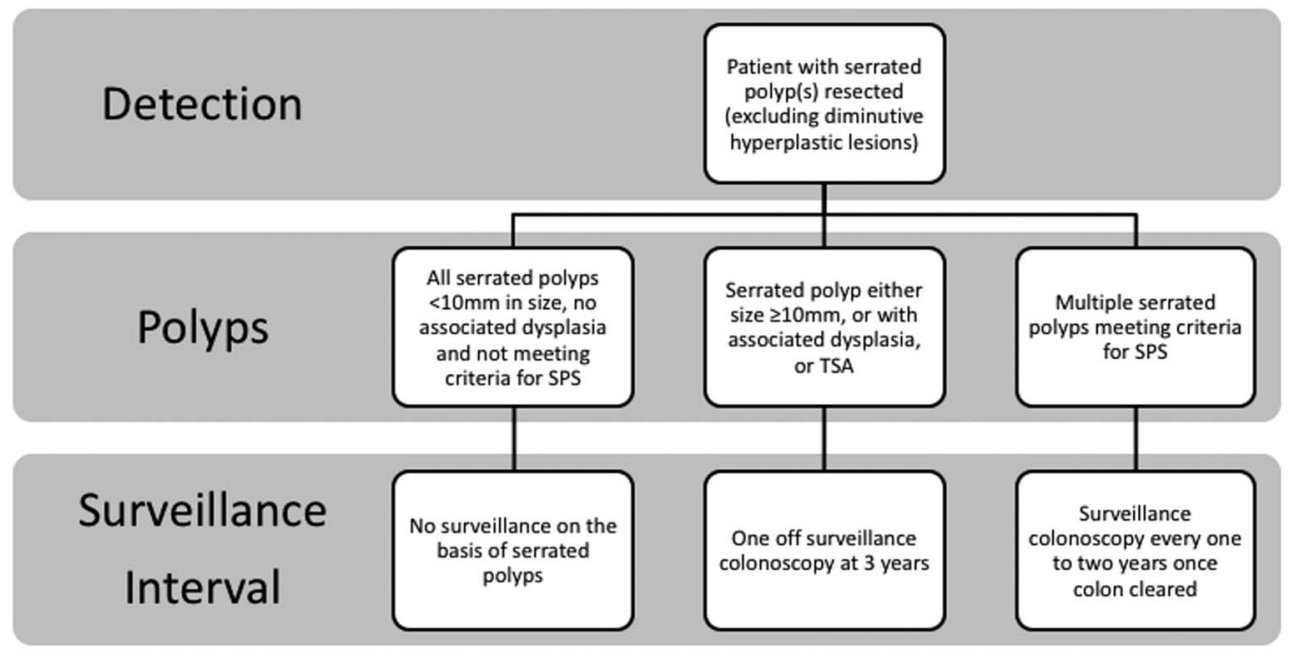

There is no current data to suggest that risk for patients with adenomas and serrated polyps is cumulative and therefore each polyp group should be considered separately for surveillance. The shortest surveillance interval recommended should take precedence. SPS, Serrated Polyposis Syndrome; TSA, traditional serrated adenoma

Figure 2 Serrated surveillance flow chart.

surveillance more likely. ${ }^{118} 119$ There is evidence they are also associated with neoplasia. Patients with baseline advanced adenomas and proximal SSA/P were more likely to have advanced neoplasia detected at follow-up, however, this was not the case for baseline tubular adenomas. ${ }^{120}$ In addition, a retrospective study found that $15 \%$ of patients with SSA/P at baseline endoscopy had advanced neoplasia over an 8.3-year follow-up. ${ }^{115}$

\section{Higher risk lesions}

There is evidence that larger SSA/Ps $(\geq 10 \mathrm{~mm})$ are predictive of advanced neoplasia 5152 120-124 with a number of studies demonstrating that this association is synchronous. ${ }^{50-52} 120-122125$ Furthermore, increasing size of SSA/P has been associated with dysplasia and found to be predictive of CRC. ${ }^{122} 123126 \mathrm{SSA} / \mathrm{P}$ prevalence as well as the presence of dysplasia is associated with increasing age, ${ }^{126}{ }^{127}$ but the risk and rate of progression of SSA/P to dysplasia and cancer has not been clearly delineated. However, a mean progression interval of 15 years from SSA/P without cytological dysplasia to cancer has been suggested. ${ }^{48}$

There is discrepancy in the reported risk of metachronous CRC in the setting of SSA/P. Some studies have found that there is no evidence of increased risk of metachronous CRC. ${ }^{51} 118119$ However, a recent study found an HR for CRC of 2.5 (95\% CI 0.8 to 7.8 ) in individuals with large serrated polyps, equivalent to that of advanced adenomas. ${ }^{123}$ Other studies also support $\mathrm{SSA} / \mathrm{P}$ as an independent risk factor for CRC, with incidence significantly higher in patients with SSA than control patients with hyperplastic and adenomatous polyps. ${ }^{115}$ A large Danish population-based study has recently suggested that SSA/Ps are risk equivalent to adenomas in terms of future long-term CRC risk, with SSPs with dysplasia and TSAs being particularly high risk ${ }^{128}$ (see figure 2).
The US Multi-Society Task Force on CRC guidelines from 2012 and the European Society of GI Endoscopy polyp surveillance guidelines from 2013 both recommend a surveillance examination at 3 years for patients with a single SSP $\geq 10 \mathrm{~mm}$ in size. $^{111} 129$

\section{Statement 8}

We suggest that until further evidence on the efficacy or otherwise of surveillance are published, patients with SSLs that appear associated with a higher risk of future neoplasia or CRC (SSLs $\geq 10 \mathrm{~mm}$ or SLs harbouring dysplasia including TSAs) should be offered a one-off colonoscopic surveillance examination at 3 years (weak recommendation, low quality evidence, $90 \%$ agreement).

\section{Lower risk lesions}

Diminutive HPs in the rectosigmoid are not thought to be risk markers for future CRC risk. Whether one or two proximal small or diminutive HPs or SSLs are risk markers for future CRC is unclear, with studies reporting risk showing most risk is associated with larger lesions (see High risk lesions). Pathological distinction of HPs and SSLs also becomes more challenging as lesion size decreases. Similar to data for adenomas, the number of SSA/P has also been implicated in a retrospective study where three or more serrated polyps were an independent predictor of synchronous advanced neoplasia. ${ }^{121}$ Overall, data are limited to support any significant excess risk of small SSA/P. Multiple serrated polyps $<10 \mathrm{~mm}$ in size, especially in a young patient, might represent an incomplete phenotypic expression of SPS and therefore surveillance in this setting needs to be individualised to the size, location and pathology of the lesions in an individual patient (see figure 2). 


\section{Statement 9}

We suggest that at present for HPs or SSLs $<10 \mathrm{~mm}$ in size without dysplasia there is no clear indication for colonoscopic surveillance unless sufficient in size, location and number to meet the criteria for SPS (weak recommendation, very low quality evidence, $90 \%$ agreement).

\section{Other considerations}

There are no data on longitudinal risk after polypectomy, however, one study has demonstrated $47 \%$ of large SSA/P that underwent polypectomy were incompletely removed. ${ }^{103}$ There are multiple case reports describing carcinomas arising from SSA $/ P^{20}{ }^{21}{ }^{130-132}$ and interval cancers are more likely to be derived from the serrated pathway. ${ }^{133}$ However, in a study where 23 large serrated polyps were left in situ for a median of 11.0 years, none of these developed malignant tumour. ${ }^{123}$

\section{SPECIAL SITUATIONS: SPS AND SERRATED POLYPS IN COLITIS}

\section{Serrated polyposis syndrome}

Serrated polyps can be multiple and if present in sufficient numbers and size can meet the criteria for SPS (previously called HP syndrome; WHO definition, box 3).

Estimates of the prevalence of SPS in the population have traditionally been very low, with figures of 1:100 000 quoted; however, in screening populations the prevalence may be higher. In FOBT-based screening, the prevalence of SPS may exceed $1: 300$, although the rate in colonoscopy-based programmes is approximately 1:2000, making this an important syndrome for screening colonoscopists to recognise in these programmes (table 3). ${ }^{134-138}$

SPS was originally described to avoid misclassification as familial adenomatous polyposis (FAP), and was not thought to confer any increased risk of CRC; ${ }^{139}$ however, this was challenged in 1996 where a case series of CRC associated with SPS was described. ${ }^{32}$ Subsequent larger recent series from the Netherlands and the USA have confirmed an increased risk of CRC during colonoscopic surveillance of $7 \%$ at 5 years and two cancers in 44 patients over 2 years, ${ }^{140}{ }^{141}$ although these estimates may be inflated by ascertainment bias, and a recent large international multicentre series reported a lower rate of 1.9 events/1000 person-years surveillance (95\% CI 0.3 to 6.4$).{ }^{142} \mathrm{~A}$ multicentre Spanish series also reported a lower than previously reported risk, $1.9 \%$ CRC risk at 5 years. ${ }^{143}$

Table 3 Serrated polyposis syndrome prevalence in population-based screening by modality (adapted from East et al ${ }^{68}$ )

\begin{tabular}{llcll}
\hline Author & $\begin{array}{l}\text { Screening } \\
\text { modality }\end{array}$ & n/pop & $\%(95 \%$ Cl) & Ratio \\
\hline Lockett & $\begin{array}{l}\text { Flexible } \\
\text { sigmoidoscopy }\end{array}$ & $12 / 40674$ & $0.029 \%(0.02$ to 0.05$)$ & $1: 3000$ \\
Orlowska & Colonoscopy & $28 / 50148$ & $0.056 \%(0.04$ to 0.09$)$ & $1: 1791$ \\
Kahi & Colonoscopy & $3 / 6681$ & $0.04 \%(0.01$ to 0.014$)$ & $1: 2227$ \\
Biswas & FOBT (guaiac) & $5 / 755$ & $0.66 \%(0.24$ to 1.52$)$ & $1: 151$ \\
Moreira & FOBT (FIT) & $8 / 2355$ & $0.34 \%(0.17$ to 0.67$)$ & $1: 294$ \\
\hline
\end{tabular}

FOBT, faecal occult blood test; FIT, faecal immunochemical test.
In a series from the same group in the Netherlands and from an international cohort the risk of CRC in first-degree relative was five times that of the general population. ${ }^{144}$ In common with other colonic polyposis, there has been consideration of whether extracolonic GI polyposis (upper GI tract of small bowel) exists, with none reported, ${ }^{141}$ or whether there might be an association with extracolonic cancers. No report confirms an association with extracolonic carcinoma; however, one report indicated an association with pancreatic carcinoma in first-degree relatives of patients with SPS, which has not been supported in another case series. ${ }^{145} 146$

\section{Statement 10 \\ We suggest that upper GI surveillance for polyposis or extraluminal surveillance for non-GI cancers is not necessary in patients with SPS where other genetic causes have been excluded (weak recommendation, very low quality evidence, $100 \%$ agreement).}

Given the multiple polyps, high risk of CRC, evidence of familial clustering, associated family history of CRC in $50 \%$ of cases and increased risk of CRC in first-degree relatives, there has been a concerted effort to find a genetic cause for SPS. Genes (and associated syndromes) associated with an SPS phenotype include: MUTYH (MAP); BMPR1A (juvenile polyposis syndrome); ${ }^{147}$ SMAD4 (juvenile polyposis syndrome); ${ }^{148}{ }^{149}$ PTEN (Cowden syndrome ${ }^{150}$ ); GREM1 (hereditary mixed polyposis syndrome ${ }^{151}$ ); RNF43 (multiple serrated polyp ${ }^{152}$ ). However, no genetic mutation is identified for the majority of cases. In a series of 65 individuals fulfilling the WHO criterion 1 or 3 , systematically investigated for mutations in these genes, no significant abnormalities were found. ${ }^{153}$ Thus, while determining whether an individual fulfils the WHO definition of SPS is relatively straightforward; the phenotypic overlap with other syndromes is an important potential pitfall. We therefore recommend that all patients with a clinical diagnosis of SPS are referred to a clinical genetics unit or dedicated polyposis registry to ensure that an alternative diagnosis is not missed.

In addition, centralisation of individuals and families into such units allows appropriate recall for surveillance, identification of relatives who should also have surveillance and facilitates research into SPS and its underlying genetics.

\section{Statement 11 \\ We suggest that all patients with SPS should be referred to clinical genetics services or a polyposis registry, where local resources allow (weak recommendation, very low quality evidence, $100 \%$ agreement).}

On the same basis as other polyposis syndrome, for example, attenuated FAP, endoscopic management may be appropriate if the size, location and number of polyps are manageable, the patient is willing and the appropriate endoscopic skill set is available (usually tertiary centres). A recent series for Amsterdam suggests that once the colon is cleared relatively few patients (3/41) need surgery during 5 years of intensive surveillance with no cancer developing ${ }^{154}$ (for position statement see the 'Surveillance strategies after detection of SLs' section). 
Statement (repeated from surveillance section) 6 We suggest that given the elevated CRC risk in patients who meet the WHO criteria for SPS, and that effective surveillance appears to reduce CRC risk, these patients should be offered one to two yearly colonoscopic surveillance (weak recommendation, low quality evidence, $90 \%$ agreement).

However, in the same series 26 of 78 inception patients came to surgery for cancer at presentation, extensive polyposis or high risk or unresectable polyps. ${ }^{154}$ As with other polyposis syndromes therefore, surgical resection should be seriously considered when colonoscopic removal of polyps is not feasible, in order to reduce cancer risk. ${ }^{155}$ These surgical principles apply when cancer is detected in the context of SPS.

\section{Statement 12}

We suggest that surgery should be considered in patients with SPS who have lesions that are not amenable to colonoscopic resection because of their size, site or number (weak recommendation, very low quality evidence, $100 \%$ agreement).

We suggest that surgery should aim to remove all lesions that are not amenable to endoscopic resection, and could take the form of: segmental colectomy, total colectomy with ileorectal anastomosis or proctocolectomy (with or without ileoanal pouch formation) depending on the lesion burden and distribution (weak recommendation, very low quality evidence, 100\% agreement).

\section{Serrated polyps in colitis}

Patients with longstanding extensive colitis have an increased risk of developing CRC. Although many colitis-associated cancers may develop from sporadic adenomas (the adenomacarcinoma sequence), it is recognised that a proportion of cancers in patients with colitis arise from an inflammationcancer pathway involving a different frequency, sequence and timing of molecular events (eg, earlier loss of Adenomatous Polyposis Coli (APC) function and later p53 mutation) compared with sporadic, non-IBD-related carcinogenesis. Very little consideration has been given to the possibility of a serrated dysplasia pathway for inflammation-driven carcinogenesis in colitis.

\section{Incidence}

Serrated polyps do occur in IBD; however, the incidence of SLs in patients with colitis is unknown. Historical studies may be unreliable, due to under-reporting of a lesion that was previously believed to be of no clinical significance and the lesions may be even more difficult to identify in inflamed mucosa.

Several studies have reviewed pathology specimens to determine the incidence of serrated histology in colitis-associated neoplasia. Bossard et al ${ }^{156}$ reported that serrated preneoplastic lesions accounted for $6.9 \%(2 / 29)$ of all preneoplastic lesions in inflamed IBD mucosa, a lower proportion than that seen in patients without IBD, although this may be due to sample size. Rubio compared the histological phenotypes of neoplasia in 96 colectomy specimens in patients with colitic cancer. ${ }^{157}$ In colitis, a dysplastic serrated pattern occurred in $12 \%$ of the neoplasia in circumscribed Dysplasia Associated Lesion or Mass (DALM)-type lesions and in 29\% of the adenomatous (Adenoma Like Mass (ALM)) lesions with well-defined borders surrounded by non-dysplastic colorectal mucosa; however, the invading cancer phenotype was serrated in only in $4 \%$ of the colitic cancers . In an earlier study by Rubio et al, ${ }^{158}$ the histological phenotype of dysplasia adjacent to CRCs was assessed in $50 \mathrm{IBD}$ and 50 non-IBD colectomy specimens. Serrated neoplasia accounted for $28.9 \%$ (11 out of 38 ) of the non-invasive dysplastic lesions abutting IBD carcinomas but only 3.4\% (1 out of 29) of control specimens. Aust $e t a l^{159}$ demonstrated activating $B R A F$ mutations typical of SSPs were identified in 9\% (3 out of 33) of colitis-associated cancers, consistent with the hypothesis that some colitis-associated cancers may arise through the serrated pathway.

\section{Different pathways to neoplasia}

As described above, it is clear that some cancers in colitis have associated serrated histopathology; what is unknown is whether this serrated pathway is promoted by colitic inflammation or coincidental to it. Several studies paint a rather mixed picture. Odze $e t a l^{160}$ found no significant difference in the prevalence of KRAS mutations, loss of heterozygosity of APC, $3 p, p 53$ or p16, between chronic UC-associated HPs (not SSPs per se), sporadic HPs and inflamed colitic mucosa. Srivastava et al ${ }^{161}$ reported three patients with longstanding IBD who developed numerous hyperplastic/serrated colonic polyps similar to those described in the SPS. Two patients had CRC. KRAS mutation was detected in $45 \%(5 / 11)$ polyps and the mucinous adenocarcinoma, more than expected for the standard serrated pathway. Moreover, BRAF mutations were not identified in any of the serrated polyps tested, raising the possibility of a separate IBD-serrated pathway. Bossard et al ${ }^{156}$ retrospectively reviewed neoplastic lesions from 36 patients with IBD. These included one HP and one TSA, both of which exhibited the V600E BRAF mutation without MSI or MMR deficiency. The TSA was close to a mucinous adenocarcinoma, which exhibited the BRAF mutation and MSI with loss of hMLH1. This is consistent with the sequence of molecular events described in the serrated pathway.

KRAS mutations are uncommon in the serrated pathway, but are observed preferentially in sporadic colorectal carcinogenesis. KRAS activating mutations occur very early in IBD-related carcinogenesis, as evidenced by KRAS mutations being detected in control inflammatory non-dysplastic mucosa. ${ }^{156}$ This suggests that the serrated pathway is distinct from the inflammationcancer pathway and that thus far there is no clear evidence to suggest that SLs seen in colitis are more common that might be seen sporadically. Therefore, there may be no specific colitis-associated SL, in contrast to the accepted concept of colitis-associated dysplasia/cancer. The strength of the data available means no statement on SLs in colitis was felt to be appropriate at this time.

\section{EDUCATION, AUDIT AND BENCHMARKS AND RESEARCH QUESTIONS}

\section{Pathological and endoscopic images of SLS}

Video demonstration of technique for en bloc hot snare EMR of a $12 \mathrm{~mm}$ right-sided SSL: https://www.youtube.com/watch? $\mathrm{v}=\mathrm{Z}_{-} \mathrm{GKfMmRve} 0$.

\section{Statement 13 \\ We recommend that clinicians involved in the care of patients with serrated polyps, especially endoscopists and pathologists, acquire the knowledge and skills to recognise and differentiate the various types of SLs (strong recommendation, moderate quality evidence, $100 \%$ agreement).}


Figure 3 (A) A $15 \mathrm{~mm}$ sessile serrated lesion without dysplasia in the right colon. Note the adherent mucus cap which aids detection. (B) The same lesion after washing and application of indigocarmine dye-spray to clarify lesion boarders and extent. (C) Lesion lifted with dilute methylene blue in lifting solution providing contrasting background to aid precise resection. (D) Postpolypectomy defect after cold snare piecemeal endoscopic mucosal resection.
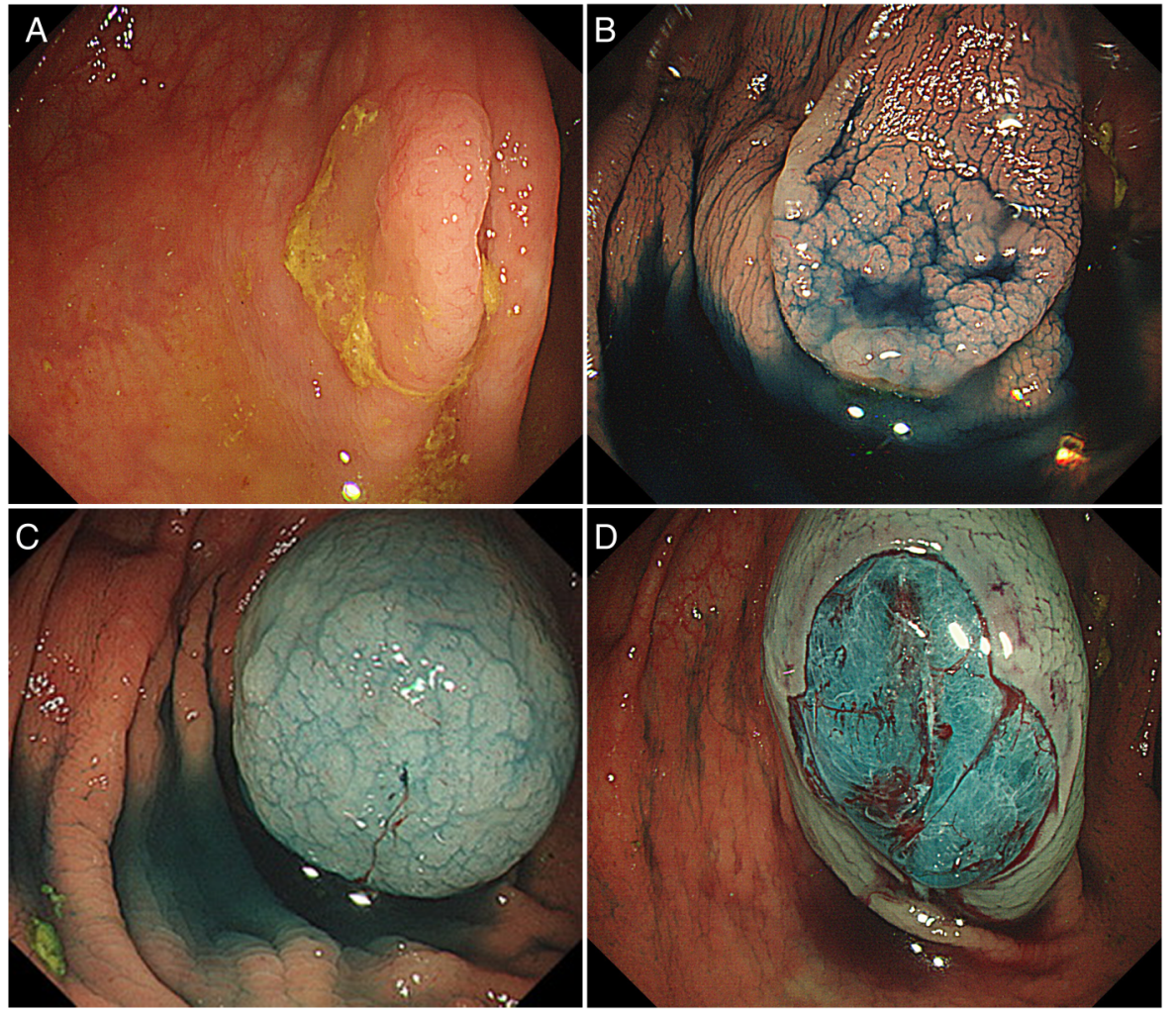

Given the accepted importance of the serrated pathway in clinical practise for gastroenterologists, surgeons and pathologists, we would recommend that knowledge in these areas be incorporated into the new national gastroenterology curriculum for higher training (figures 3A-D and 4A-D).

\section{Audit and benchmarks}

The ADR is now an accepted quality marker for colonoscopy, for both general (BSG Quality and Safety indicators) and for screening colonoscopy. ${ }^{162}$ There is some evidence that the ADR correlates with SSL-DR ${ }^{41}$ and proximal SL-DR ${ }^{69} 135$

The overall detection rates for SLs (ie, percentage of colonoscopes with $\geq 1$ such lesion) have been reported as $4 \%$ $35 \%$ in average-risk screening populations, ${ }^{35}$ 50-53 55-57 163$16513 \%-21 \%{ }^{125} 165$ in unselected populations (ie, symptomatic as well as screening patients) and $10 \%$ in surveillance patients (table 1). ${ }^{163}$ A number of studies have also shown that the DR for proximal SLs is 3\%-13\% in screening populations. 35 51-53 55135164
Figure 4 (A) A microvesicular hyperplastic polyp showing serration within the upper half of the lesion and with none of the characteristic features of a sessile serrated lesion (SSL) (magnification $\times 100$ ). (B) An SSL showing pronounced serration at the crypt base and horizontal spreading of a crypt, forming a typical ' $\mathrm{L}$ ' or 'boot' shape (magnification $\times 200$ ). (C) An SSL showing a sharp distinction between areas showing no dysplasia and low-grade dysplasia (magnification $\times 100$ ). (D) A traditional serrated adenoma (TSA) showing a pronounced villous growth pattern, pencillate nuclei, eosinophilic cytoplasm and ectopic crypt foci (magnification $\times 200$ ). (Reproduced from Bateman and Shepherd, ${ }^{37}$ with permission from BMJ Publishing Group.)
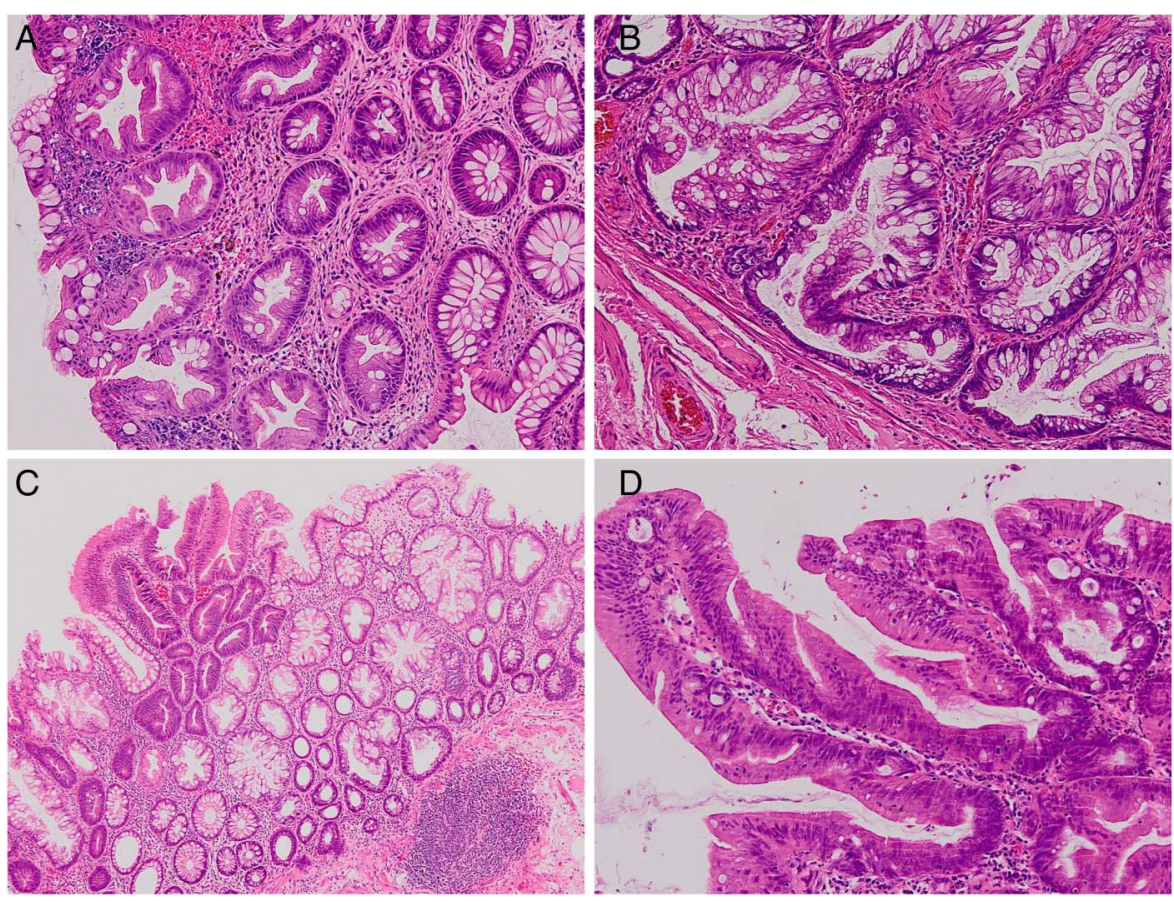
Focussing on SSLs, the DR has been reported as $0.6 \%-11 \%$ in screening populations, ${ }^{41505257166}$ and 5\% in an unselected population (table 1). ${ }^{167}$ Detection rates for TSAs in screening populations has been have been shown to be $<1 \% .{ }^{50} 52$ Three studies have reported DRs of $1 \%-11 \%$ for all serrated adenomas in screening populations. ${ }^{5156164}$

Other studies have investigated DRs for 'significant SLs' such as large SPs (DR 1.8\%-2.3\% $\%^{51} 164$ in average-risk screening populations, and dysplastic/large proximal non-dysplastic SLs in an unselected population (DR $2.5 \%{ }^{125}$ ).

Any attempt to set a benchmark for SL-DR needs to take into account that there is considerable variability in the detection rates for individual endoscopists. Results from a single-centre study of 7192 patients undergoing screening colonoscopes by 13 different endoscopists revealed that SSL detection per 100 colonoscopes ranged from 0 in the lowest detector to 2.2 in the highest detector. ${ }^{41}$ The detection rate of PSLs ranged from 1\% to $18 \%$ among 15 different endoscopists at the two US centres in a study of 6681 patients undergoing average-risk screening. ${ }^{135}$ The results of these two retrospective studies are supported by a prospective study from the Netherlands of 1426 people undergoing colonoscopic screening; the PSP-DR ranged from $6 \%$ to $22 \%$ among five different endoscopists. ${ }^{69}$

While endoscopic skills are undoubtedly important, the detection rates for SLs are also influenced by the quality of pathology reporting. Payne et al have recently reported a multicentre US and German study; detection rates for SLs (defined as SSA/P, SSA with dysplasia or HPs $>1 \mathrm{~cm}$ in the proximal colon) ranged from $0 \%$ to $13.1 \%$ among the 32 centres, with four centres reporting no PSLs at all over the 2-year period of the study. Guidance for the pathological diagnosis of SLs has recently been published in the $\mathrm{UK}^{37}$ and this will be reinforced within the updated Reporting Lesions in the NHS Bowel Cancer Screening Programme document that is due to be published in 2017. We envisage that these publications will help to reduce interobserver variability between pathologists during the assessment of SLs. A high-quality histology report for a SL should include the lesion type (according to the classification system in box 2), size, presence and grade of any dysplasia; and proximity to the diathermy/ stalk margin if this is practically possible.

The detection rate may also be influenced by ethnicity as demonstrated in a single-centre, and single endoscopist, study from Australia, which revealed that the SSL-DR was significantly higher in Caucasians when compared with Chinese $(7.0 \%$ vs $2.0 \%) .{ }^{167}$ This was also seen in a necropsy study from New Zealand. ${ }^{42}$

With the caveats mentioned above, it is clear that SLs can be detected at colonoscopy and in view of the importance of the SL pathway in the development of right-sided CRC, setting a quality standard for their detection would be an important step towards reducing the risk of proximal CRC. Kahi et $a l^{135}$ have attempted to set such a benchmark for proximal SLs; based on a retrospective analysis of two colonoscopy databases, the maximum detection rate was approximately $20 \%$ in screening populations. In view of the correlation between the PSL-DR and the ADR, the authors used linear regression to model the relationship between adenoma detection and PSP detection for each endoscopist and to derive PSP detection rates corresponding to ADRs of $25 \%$ in men and $15 \%$ in women. ${ }^{168}$ The PSL-DR was demonstrated to be $5 \%$ for both men and women. Recent Dutch data suggest that the PSP detection rate is strongly correlated with the clinically relevant serrated polyp detection rate $(\mathrm{R}=0.94)$, but less so for ADR $(\mathrm{R}=0.54)$, supporting PSP detection rate as a benchmark. ${ }^{169}$

\section{Statement 14}

We suggest that benchmarking SL detection rates is challenging and affected by case mix, patient ethnicity, histopathological diagnosis and the inclusion of distal SLS; however, endoscopists who wish to assess their PSP detection rate might aim for a detection rate $>5 \%$ (weak recommendation, low quality evidence, $88 \%$ agreement).

\section{Research questions}

- What molecular markers predict the future malignant potential of SSPs.

- How can we increase accuracy and decrease interobserver variability between pathologists assessing SSPs?

- Which technologies and techniques will increase the detection of SLs at colonoscopy?

- Will intensive detection, removal and surveillance of proximal SSPs result in significant reduction in mortality from colorectal cancer and all-cause mortality.

- What would be the appropriate surveillance interval for proximal SSPs with and without coexisting colorectal cancer and coexisting adenomas.

- Is surveillance for SLs cost-effective?

- What chemopreventive measures would reduce the development and growth of SLs and associated cancers?

- What biomarkers can select patients at high risk of SLs?

- How can we integrate SSP into current paradigms for 'optical biopsy' at colonoscopy?

- How can training in recognition and resection of SLs be optimised?

\section{Statement 15}

We suggest that the current evidence base for clinical decision making for patients with SLs is poor. Clinicians are strongly advised to support prospective studies that will bolster this evidence and avoid empirical management decisions, to allow formal guidelines to be developed (weak recommendation, low quality evidence, $100 \%$ agreement).

\section{Author affiliations}

${ }^{1}$ Translational Gastroenterology Unit, Nuffield Department of Medicine, University of Oxford, John Radcliffe Hospital, Oxford, UK

${ }^{2}$ Department of Surgery and Cancer, Imperial College London, London, UK ${ }^{3}$ Department of Cellular Pathology, Southampton General Hospital, Southampton, UK

${ }^{4}$ The Polyposis Registry, St. Mark's Hospital, London, UK

${ }^{5}$ Cancer Screening, Prevention and Early Diagnosis Group, Division of Population Medicine, Cardiff University, Cardiff, UK

${ }^{6}$ Gastrointestinal Stem-cell Biology Laboratory, Oxford Centre for Cancer Gene Research, Wellcome Trust Centre for Human Genetics, University of Oxford, Oxford, UK

${ }^{7}$ Department of Digestive Disorders, Aberdeen Royal Infirmary, Aberdeen, UK ${ }^{8}$ Department of Gastroenterology, University Hospital of North Tees, Stockton-onTees, Cleveland, UK

${ }^{9}$ School of Medicine, Durham University, Durham, UK

${ }^{10}$ Gloucestershire Cellular Pathology Laboratory, Cheltenham General Hospital, Cheltenham, UK

${ }^{11}$ Oxford Centre for Cancer Gene Research, Wellcome Trust Centre for Human Genetics, University of Oxford, Oxford, UK

${ }^{12}$ Department of Gastroenterology, South Tyneside NHS Foundation Trust, South Shields, UK

Competing interests JEE: Lumendi, Olympus, Cosmo Pharmaceuticals; WSA: Eiken (MAST is the UK distributor); SJL: Cancer Research UK (Grant); CJR: ARC Medical, Olympus. 
Provenance and peer review Not commissioned; externally peer reviewed.

Open Access This is an Open Access article distributed in accordance with the Creative Commons Attribution Non Commercial (CC BY-NC 4.0) license, which permits others to distribute, remix, adapt, build upon this work non-commercially, and license their derivative works on different terms, provided the original work is properly cited and the use is non-commercial. See: http://creativecommons.org/ licenses/by-nc/4.0/

\section{REFERENCES}

1 Atkins $D$, Best $D$, Briss PA, et al. Grading quality of evidence and strength of recommendations. BMJ 2004;328:1490.

2 Jaeschke R, Guyatt GH, Dellinger P, et al. Use of GRADE grid to reach decisions on clinical practice guidelines when consensus is elusive. BMJ 2008;337:a744.

3 Muto T, Bussey HJ, Morson BC. The evolution of cancer of the colon and rectum. Cancer 1975;36:2251-70.

4 Vogelstein B, Fearon ER, Hamilton SR, et al. Genetic alterations during colorectal-tumor development. N Engl J Med 1988;319:525-32.

5 East JE, Saunders BP, Jass JR. Sporadic and syndromic hyperplastic polyps and serrated adenomas of the colon: classification, molecular genetics, natural history and clinical management. Gastroenterol Clin North Am 2008;37:25-46.

6 Leggett $B$, Whitehall V. Role of the serrated pathway in colorectal cancer pathogenesis. Gastroenterology 2010;138:2088-100.

7 IJspeert JE, Vermeulen L, Meijer GA, et al. Serrated neoplasia-role in colorectal carcinogenesis and clinical implications. Nat Rev Gastroenterol Hepatol 2015;12:401-9.

8 Lane N. The precursor tissue of ordinary large bowel cancer. Cancer Res 1976;36 (Pt 2):2669-72.

9 Bettington M, Walker N, Clouston A, et al. The serrated pathway to colorectal carcinoma: current concepts and challenges. Histopathology 2013;62:367-86.

10 Weisenberger DJ, Siegmund KD, Campan M, et al. CpG island methylator phenotype underlies sporadic microsatellite instability and is tightly associated with BRAF mutation in colorectal cancer. Nat Genet 2006;38:787-93.

11 Snover DC. Update on the serrated pathway to colorectal carcinoma. Hum Pathol 2011:42:1-10.

12 Hughes LA, Khalid-de Bakker CA, Smits KM, et al. The CpG island methylator phenotype in colorectal cancer: progress and problems. Biochim Biophys Acta 2012; 1825:77-85.

13 Chan TL, Zhao W, Leung SY, et al. BRAF and KRAS mutations in colorectal hyperplastic polyps and serrated adenomas. Cancer Res 2003;63:4878-81.

14 Park SJ, Rashid A, Lee JH, et al. Frequent CpG island methylation in serrated adenomas of the colorectum. Am J Pathol 2003;162:815-22.

15 Goldstein NS, Bhanot P, Odish E, et al. Hyperplastic-like colon polyps that preceded microsatellite-unstable adenocarcinomas. Am J Clin Pathol 2003;119:778-96.

16 O'brien MJ, Yang S, Mack C, et al. Comparison of microsatellite instability, CpG island methylation phenotype, BRAF and KRAS status in serrated polyps and traditional adenomas indicates separate pathways to distinct colorectal carcinoma end points. Am I Surg Pathol 2006;30:1491-501.

17 Sheridan TB, Fenton $H$, Lewin MR, et al. Sessile serrated adenomas with low- and high-grade dysplasia and early carcinomas: an immunohistochemical study of serrated lesions "caught in the act". Am J Clin Pathol 2006;126:564-71.

18 Boparai KS, Dekker E, Polak MM, et al. A serrated colorectal cancer pathway predominates over the classic WNT pathway in patients with hyperplastic polyposis syndrome. Am J Pathol 2011;178:2700-7.

19 Tanaka M, Kusumi T, Sasaki Y, et al. Colonic intra-epithelial carcinoma occurring in a hyperplastic polyp via a serrated adenoma. Pathol Int 2001;51:215-20.

20 Yamauchi T, Watanabe $M$, Hasegawa $H$, et al. Serrated adenoma developing into advanced colon cancer in 2 years. J Gastroenterol 2002;37:467-70.

21 Oono Y, Fu K, Nakamura $H$, et al. Progression of a sessile serrated adenoma to an early invasive cancer within 8 months. Dig Dis Sci 2009;54:906-9.

22 Yamauchi M, Morikawa T, Kuchiba A, et al. Assessment of colorectal cancer molecular features along bowel subsites challenges the conception of distinct dichotomy of proximal versus distal colorectum. Gut 2012;61:847-54.

23 Torlakovic EE, Gomez JD, Driman DK, et al. Sessile serrated adenoma (SSA) vs. traditional serrated adenoma (TSA). Am J Surg Pathol 2008;32:21-9.

$24 \mathrm{Kim} \mathrm{KM}$, Lee EJ, Kim YH, et al. KRAS mutations in traditional serrated adenomas from Korea herald an aggressive phenotype. Am I Surg Pathol 2010;34:667-75.

25 Davis H, Irshad S, Bansal M, et al. Aberrant epithelial GREM1 expression initiates colonic tumorigenesis from cells outside the stem cell niche. Nat Med 2015;21:62-70.

26 Rex DK, Ahnen DJ, Baron JA, et al. Serrated lesions of the colorectum: review and recommendations from an expert panel. Am J Gastroenterol 2012;107:1315-29.

27 Whitehall VL, Walsh MD, Young J, et al. Methylation of 0-6-methylguanine DNA methyltransferase characterizes a subset of colorectal cancer with low-level DNA microsatellite instability. Cancer Res 2001;61:827-30.

28 Sawhney MS, Farrar WD, Gudiseva S, et al. Microsatellite instability in interval colon cancers. Gastroenterology 2006;131:1700-5.
29 Arain MA, Sawhney M, Sheikh S, et al. CIMP status of interval colon cancers: another piece to the puzzle. Am J Gastroenterol 2010;105:1189-95.

30 Gill P, Rafferty H, Munday D, et al. Proximal colon cancer and serrated adenomas -hunting the missing 10\%. Clin Med 2013;13:557-61.

31 Snover DC, Ahenen DJ, Burt RW, et al. Serrated polyps of the colon and rectum and serrated polyposis. In: Bosman FT, Carneiro F, Hruban RH, Theise ND, eds. World Health Organisation Classification of tumours of the digestive system. Lyon: IARC Press, 2010:160.

32 Torlakovic E, Snover DC. Serrated adenomatous polyposis in humans. Gastroenterology 1996;110:748-55.

33 Wong NA, Hunt LP, Novelli MR, et al. Observer agreement in the diagnosis of serrated polyps of the large bowel. Histopathology 2009;55:63-6.

34 Ensari A, Bilezikçi B, Carneiro F, et al. Serrated polyps of the colon: how reproducible is their classification? Virchows Arch 2012;461:495-504.

35 Payne SR, Church TR, Wandell M, et al. Endoscopic detection of proximal serrated lesions and pathologic identification of sessile serrated adenomas/polyps vary on the basis of center. Clin Gastroenterol Hepatol 2014;12:1119-26.

36 Glatz K, Pritt B, Glatz D, et al. A multinational, internet-based assessment of observer variability in the diagnosis of serrated colorectal polyps. Am J Clin Pathol 2007;127:938-45

37 Bateman AC, Shepherd NA. UK guidance for the pathological reporting of serrated lesions of the colorectum. J Clin Pathol 2015;68:585-91.

38 Kim SW, Cha JM, Lee JI, et al. A significant number of sessile serrated adenomas might not be accurately diagnosed in daily practice. Gut Liver 2010;4:498-502.

39 Khalid O, Radaideh S, Cummings OW, et al. Reinterpretation of histology of proximal colon polyps called hyperplastic in 2001. World I Gastroenterol 2009;15:3767-70.

40 Singh H, Bay D, Ip S, et al. Pathological reassessment of hyperplastic colon polyps in a city-wide pathology practice: implications for polyp surveillance recommendations. Gastrointest Endosc 2012;76:1003-8.

41 Hetzel JT, Huang CS, Coukos JA, et al. Variation in the detection of serrated polyps in an average risk colorectal cancer screening cohort. Am J Gastroenterol 2010;105:2656-64.

42 Jass JR, Young PJ, Robinson EM. Predictors of presence, multiplicity, size and dysplasia of colorectal adenomas. A necropsy study in New Zealand. Gut 1992:33:1508-14.

43 Vatn $\mathrm{MH}$, Stalsberg $\mathrm{H}$. The prevalence of polyps of the large intestine in Oslo: an autopsy study. Cancer 1982;49:819-25.

44 Johannsen LG, Momsen 0, Jacobsen NO. Polyps of the large intestine in Aarhus, Denmark. An autopsy study. Scand I Gastroenterol 1989;24:799-806.

45 Williams AR, Balasooriya BA, Day DW. Polyps and cancer of the large bowel: a necropsy study in Liverpool. Gut 1982;23:835-42.

46 Carr NJ, Mahajan H, Tan KL, et al. Serrated and non-serrated polyps of the colorectum: their prevalence in an unselected case series and correlation of BRAF mutation analysis with the diagnosis of sessile serrated adenoma. J Clin Pathol 2009;62:516-18.

47 Higuchi T, Sugihara K, Jass JR. Demographic and pathological characteristics of serrated polyps of colorectum. Histopathology 2005;47:32-40.

48 Lash RH, Genta RM, Schuler CM. Sessile serrated adenomas: prevalence of dysplasia and carcinoma in 2139 patients. J Clin Pathol 2010;63:681-6.

49 Spring KJ, Zhao ZZ, Karamatic R, et al. High prevalence of sessile serrated adenomas with BRAF mutations: a prospective study of patients undergoing colonoscopy. Gastroenterology 2006;131:1400-7.

50 Buda A, De Bone M, Dotti I, et al. Prevalence of different subtypes of serrated polyps and risk of synchronous advanced colorectal neoplasia in average-risk population undergoing first-time colonoscopy. Clin Trans/ Gastroenterol 2012;3:e6.

51 Álvarez C, Andreu M, Castells A, et al. Relationship of colonoscopy-detected serrated polyps with synchronous advanced neoplasia in average-risk individuals. Gastrointest Endosc 2013;78:333-41.

52 Hazewinkel Y, de Wijkerslooth TR, Stoop EM, et al. Prevalence of serrated polyps and association with synchronous advanced neoplasia in screening colonoscopy. Endoscopy 2014;46:219-24.

53 Lee CK, Kim YW, Shim JJ, et al. Prevalence of proximal serrated polyps and conventional adenomas in an asymptomatic average-risk screening population. Gut Liver 2013;7:524-31.

54 Kahi CJ, Hewett DG, Norton DL, et al. Prevalence and variable detection of proximal colon serrated polyps during screening colonoscopy. Clin Gastroenterol Hepatol 2011;9:42-6.

55 Min YW, Lee JH, Lee SH, et al. Prevalence of proximal colon serrated polyps in a population at average risk undergoing screening colonoscopy: a multicenter study. Clin Res Hepatol Gastroenterol 2012;36:604-8.

56 Raju GS, Vadyala V, Slack $R$, et al. Adenoma detection in patients undergoing a comprehensive colonoscopy screening. Cancer Med 2013;2:391-402.

57 Freedman JS, Harari DY, Bamij ND, et al. The detection of premalignant colon polyps during colonoscopy is stable throughout the workday. Gastrointest Endosc 2011;73:1197-206.

58 Su MY, Hsu CM, Ho YP, et al. Comparative study of conventional colonoscopy, chromoendoscopy, and narrow-band imaging systems in differential diagnosis of neoplastic and nonneoplastic colonic polyps. Am J Gastroenterol 2006;101:2711-16. 
59 Oka S, Tanaka S, Hiyama T, et al. Clinicopathologic and endoscopic features of colorectal serrated adenoma: differences between polypoid and superficial types. Gastrointest Endosc 2004;59:213-19.

60 Tadepalli US, Feihel D, Miller KM, et al. A morphologic analysis of sessile serrated polyps observed during routine colonoscopy (with video). Gastrointest Endosc 2011;74:1360-8.

61 Rustagi T, Rangasamy $P$, Myers $M$, et al. Sessile serrated adenomas in the proximal colon are likely to be flat, large and occur in smokers. World J Gastroenterol 2013;19:5271-7.

62 Hazewinkel Y, López-Cerón M, East JE, et al. Endoscopic features of sessile serrated adenomas: validation by international experts using high-resolution white-light endoscopy and narrow-band imaging. Gastrointest Endosc 2013;77:916-24.

63 Kimura T, Yamamoto E, Yamano HO, et al. A novel pit pattern identifies the precursor of colorectal cancer derived from sessile serrated adenoma. Am J Gastroenterol 2012;107:460-9.

64 Ishigooka S, Nomoto M, Obinata N, et al. Evaluation of magnifying colonoscopy in the diagnosis of serrated polyps. World J Gastroenterol 2012;18:4308-16.

65 Kim MJ, Lee EJ, Suh JP, et al. Traditional serrated adenoma of the colorectum: clinicopathologic implications and endoscopic findings of the precursor lesions. Am J Clin Pathol 2013;140:898-911.

66 Rondagh EJ, Bouwens MW, Riedl RG, et al. Endoscopic appearance of proximal colorectal neoplasms and potential implications for colonoscopy in cancer prevention. Gastrointest Endosc 2012;75:1218-25.

67 Baxter NN, Sutradhar R, Forbes SS, et al. Analysis of administrative data finds endoscopist quality measures associated with postcolonoscopy colorectal cancer. Gastroenterology 2011;140:65-72.

68 East JE, Vieth M, Rex DK. Serrated lesions in colorectal cancer screening: detection, resection, pathology and surveillance. Gut 2015;64:991-1000.

69 de Wijkerslooth TR, Stoop EM, Bossuyt PM, et al. Differences in proximal serrated polyp detection among endoscopists are associated with variability in withdrawal time. Gastrointest Endosc 2013;77:617-23.

70 Butterly L, Robinson CM, Anderson JC, et al. Serrated and adenomatous polyp detection increases with longer withdrawal time: results from the New Hampshire Colonoscopy Registry. Am J Gastroentero/ 2014;109:417-26.

71 Ket SN, Bird-Lieberman E, East JE. Electronic imaging to enhance lesion detection at colonoscopy. Gastrointest Endosc Clin N Am 2015;25:227-42.

72 Kahi CJ, Anderson JC, Waxman I, et al. High-definition chromocolonoscopy vs. high-definition white light colonoscopy for average-risk colorectal cancer screening. Am J Gastroenterol 2010;105:1301-7.

73 Pohl J, Schneider A, Vogell H, et al. Pancolonic chromoendoscopy with indigo carmine versus standard colonoscopy for detection of neoplastic lesions: a randomised two-centre trial. Gut 2011;60:485-90.

74 Chandran S, Parker F, Vaughan R, et al. Right-sided adenoma detection with retroflexion versus forward-view colonoscopy. Gastrointest Endosc 2015;81:608-13.

75 Rondonotti E, Zolk O, Amato A, et al. The impact of hyoscine-N-butylbromide on adenoma detection during colonoscopy: meta-analysis of randomized, controlled studies. Gastrointest Endosc 2014;80:1103-12.

76 Anderson JC, Butterly LF, Robinson CM, et al. Impact of fair bowel preparation quality on adenoma and serrated polyp detection: data from the New Hampshire Colonoscopy Registry by using a standardized preparation-quality rating. Gastrointest Endosc 2014;80:463-70.

77 Leufkens AM, DeMarco DC, Rastogi A, et al. Effect of a retrograde-viewing device on adenoma detection rate during colonoscopy: the TERRACE study. Gastrointest Endosc 2011;73:480-9.

78 Gralnek IM, Siersema PD, Halpern Z, et al. Standard forward-viewing colonoscopy versus full-spectrum endoscopy: an international, multicentre, randomised, tandem colonoscopy trial. Lancet Oncol 2014;15:353-60.

79 Gralnek IM, Suissa A, Domanov S. Safety and efficacy of a novel balloon colonoscope: a prospective cohort study. Endoscopy 2014;46:883-7.

80 East JE, Stavrindis M, Thomas-Gibson S, et al. A comparative study of standard vs. high definition colonoscopy for adenoma and hyperplastic polyp detection with optimized withdrawal technique. Aliment Pharmacol Ther 2008;28:768-76.

81 Subramanian V, Mannath J, Hawkey CJ, et al. High definition colonoscopy vs. standard video endoscopy for the detection of colonic polyps: a meta-analysis. Endoscopy 2011:43:499-505.

82 Boparai KS, van den Broek FJ, van Eeden S, et al. Increased polyp detection using narrow band imaging compared with high resolution endoscopy in patients with hyperplastic polyposis syndrome. Endoscopy 2011;43:676-82.

83 Hazewinkel Y, Tytgat KM, van Leerdam ME, et al. Narrow-band imaging for the detection of polyps in patients with serrated polyposis syndrome: a multicenter, randomized, back-to-back trial. Gastrointest Endosc 2015;81:531-8.

84 Aminalai A, Rösch T, Aschenbeck J, et al. Live image processing does not increase adenoma detection rate during colonoscopy: a randomized comparison between FICE and conventional imaging (Berlin Colonoscopy Project 5, BECOP-5). Am J Gastroenterol 2010;105:2383-8.

85 Chung SJ, Kim D, Song JH, et al. Comparison of detection and miss rates of narrow band imaging, flexible spectral imaging chromoendoscopy and white light at screening colonoscopy: a randomised controlled back-to-back study. Gut 2014;63:785-91.

86 Pohl J, Lotterer E, Balzer C, et al. Computed virtual chromoendoscopy versus standard colonoscopy with targeted indigocarmine chromoscopy: a randomised multicentre trial. Gut 2009;58:73-8.

87 Hoffman A, Loth L, Rey JW, et al. High definition plus colonoscopy combined with i-scan tone enhancement vs. high definition colonoscopy for colorectal neoplasia: a randomized trial. Dig Liver Dis 2014;46:991-6.

88 Hong SN, Choe WH, Lee JH, et al. Prospective, randomized, back-to-back trial evaluating the usefulness of i-SCAN in screening colonoscopy. Gastrointest Endosc 2012;75:1011-21.

89 Testoni PA, Notaristefano C, Vailati C, et al. High-definition colonoscopy with i-Scan: better diagnosis for small polyps and flat adenomas. World J Gastroenterol 2012;18:5231-9.

90 Rex DK, Clodfelter R, Rahmani F, et al. Narrow-band imaging versus white light for the detection of proximal colon serrated lesions: a randomized, controlled trial. Gastrointest Endosc 2016:83:166-71.

91 Leung FW, Leung JW, Siao-Salera RM, et al. The water method significantly enhances detection of diminutive lesions (adenoma and hyperplastic polyp combined) in the proximal colon in screening colonoscopy-data derived from two RCT in US veterans. J Interv Gastroenterol 2011:1:48-52.

92 Corte C, Dahlenburg L, Selby W, et al. Hyoscine butylbromide administered at the cecum increases polyp detection: a randomized double-blind placebo-controlled trial. Endoscopy 2012;44:917-22.

93 Park SH, Kim SY, Lee SS, et al. Sensitivity of CT colonography for nonpolypoid colorectal lesions interpreted by human readers and with computer-aided detection. AJR Am J Roentgenol 2009;193:70-8.

$94 \mathrm{Kim} \mathrm{DH}$, Hinshaw JL, Lubner MG, et al. Contrast coating for the surface of flat polyps at CT colonography: a marker for detection. Eur Radiol 2014;24:940-6.

95 Waldock A, Ellis IO, Armitage NC, et al. Histopathological assessment of bleeding from polyps of the colon and rectum. J Clin Pathol 1989;42:378-82.

96 Heigh RI, Yab TC, Taylor WR, et al. Detection of colorectal serrated polyps by stool DNA testing: comparison with fecal immunochemical testing for occult blood (FIT). PLOS ONE 2014;9:e85659.

97 Lidgard GP, Domanico MJ, Bruinsma JJ, et al. Clinical performance of an automated stool DNA assay for detection of colorectal neoplasia. Clin Gastroenterol Hepatol 2013:11:1313-18.

98 Imperiale TF, Ransohoff DF, Itzkowitz SH, et al. Multitarget stool DNA testing for colorectal-cancer screening. N Engl J Med 2014;370:1287-97.

99 Rex DK, Adler SN, Aisenberg J, et al. Accuracy of capsule colonoscopy in detecting colorectal polyps in a screening population. Gastroenterology 2015;148:948-57.

100 Hoff G, Bretthauer M, Garborg K, et al. New polyps, old tricks: controversy about removing benign bowel lesions. BMJ 2013;347:f5843.

101 Heldwein W, Dollhopf M, Rösch T, et al. The Munich Polypectomy Study (MUPS): prospective analysis of complications and risk factors in 4000 colonic snare polypectomies. Endoscopy 2005;37:1116-22.

102 Rutter MD, Nickerson C, Rees CJ, et al. Risk factors for adverse events related to polypectomy in the English Bowel Cancer Screening Programme. Endoscopy 2014;46:90-7

103 Pohl H, Srivastava A, Bensen SP, et al. Incomplete polyp resection during colonoscopy-results of the complete adenoma resection (CARE) study. Gastroenterology 2013;144:74-80.

104 Rutter MD, Chattree A, Barbour JA, et al. British Society of Gastroenterology/ Association of Coloproctologists of Great Britain and Ireland guidelines for the management of large non-pedunculated colorectal polyps. Gut 2015;64:1847-73.

105 Pellise M, Burgess NG, Tutticci N, et al. Endoscopic mucosal resection for large serrated lesions in comparison with adenomas: a prospective multicentre study of 2000 lesions. Gut 2017;66:644-53.

106 Binmoeller KF, Weilert F, Shah J, et al. "Underwater" EMR without submucosal injection for large sessile colorectal polyps (with video). Gastrointest Endosc 2012;75:1086-91.

107 Pattullo V, Bourke MJ, Tran KL, et al. The suction pseudopolyp technique: a novel method for the removal of small flat nonpolypoid lesions of the colon and rectum. Endoscopy 2009;41:1032-7.

108 Buchner AM, Guarner-Argente C, Ginsberg GG. Outcomes of EMR of defiant colorectal lesions directed to an endoscopy referral center. Gastrointest Endosc 2012;76:255-63.

109 Burgess NG, Metz AJ, Williams SJ, et al. Risk factors for intraprocedural and clinically significant delayed bleeding after wide-field endoscopic mucosal resection of large colonic lesions. Clin Gastroenterol Hepatol 2014;12:651-61.

110 Metz AJ, Bourke MJ, Moss A, et al. Factors that predict bleeding following endoscopic mucosal resection of large colonic lesions. Endoscopy 2011;43:506-11.

111 Lieberman DA, Rex DK, Winawer SJ, et al. Guidelines for colonoscopy surveillance after screening and polypectomy: a consensus update by the US Multi-Society Task Force on Colorectal Cancer. Gastroenterology 2012;143:844-57.

112 Hassan C, Repici A, Rex DK. Serrated polyposis syndrome: risk stratification or reduction? Gut 2016:65:1070-2. 
113 Oquiñena S, Guerra A, Pueyo A, et al. Serrated polyposis: prospective study of first-degree relatives. Eur J Gastroenterol Hepatol 2013;25:28-32.

114 Khashab M, Eid E, Rusche M, et al. Incidence and predictors of "late" recurrences after endoscopic piecemeal resection of large sessile adenomas. Gastrointest Endosc 2009;70:344-9.

115 Lu Fl, van Niekerk de W, Owen D, et al. Longitudinal outcome study of sessile serrated adenomas of the colorectum: an increased risk for subsequent right-sided colorectal carcinoma. Am J Surg Pathol 2010:34:927-34.

116 Pai RK, Hart J, Noffsinger AE. Sessile serrated adenomas strongly predispose to synchronous serrated polyps in non-syndromic patients. Histopathology 2010;56:581-8

117 Lazarus R, Junttila $\mathrm{OE}$, Karttunen TJ, et al. The risk of metachronous neoplasia in patients with serrated adenoma. Am J Clin Pathol 2005;123:349-59.

118 Teriaky A, Driman DK, Chande N. Outcomes of a 5-year follow-up of patients with sessile serrated adenomas. Scand I Gastroenterol 2012;47:178-83.

119 Salaria SN, Streppel MM, Lee LA, et al. Sessile serrated adenomas: high-risk lesions? Hum Pathol 2012:43:1808-14.

120 Schreiner MA, Weiss DG, Lieberman DA. Proximal and large hyperplastic and nondysplastic serrated polyps detected by colonoscopy are associated with neoplasia. Gastroenterology 2010;139:1497-502.

$121 \mathrm{Ng} \mathrm{SC}$, Ching JY, Chan VC, et al. Association between serrated polyps and the risk of synchronous advanced colorectal neoplasia in average-risk individuals. Aliment Pharmacol Ther 2015;41:108-15.

122 Hiraoka S, Kato J, Fujiki S, et al. The presence of large serrated polyps increases risk for colorectal cancer. Gastroenterology 2010;139:1503-10, 1510.

123 Holme $\varnothing$, Bretthauer $\mathrm{M}$, Eide TJ, et al. Long-term risk of colorectal cancer in individuals with serrated polyps. Gut 2015;64:929-36.

124 Li D, Jin C, McCulloch C, et al. Association of large serrated polyps with synchronous advanced colorectal neoplasia. Am J Gastroenterol 2009; 104:695-702.

125 Rondagh EJ, Masclee AA, Bouwens MW, et al. Endoscopic red flags for the detection of high-risk serrated polyps: an observational study. Endoscopy 2011;43:1052-8.

126 Burgess NG, Pellise M, Nanda KS, et al. Clinical and endoscopic predictors of cytological dysplasia or cancer in a prospective multicentre study of large sessile serrated adenomas/polyps. Gut 2016;65:437-46.

127 Kim HY, Kim SM, Seo JH, et al. Age-specific prevalence of serrated lesions and their subtypes by screening colonoscopy: a retrospective study. BMC Gastroenterol 2014;14:82.

128 Erichsen R, Baron JA, Hamilton-Dutoit SJ, et al. Increased risk of colorectal cancer development among patients with serrated polyps. Gastroenterology 2016;150:895-902.

129 Hassan C, Quintero E, Dumonceau JM, et al. Post-polypectomy colonoscopy surveillance: European Society of Gastrointestinal Endoscopy (ESGE) Guideline. Endoscopy 2013;45:842-51.

130 Xu S, Wang L, Yang G, et al. Clinicopathological observations of colorectal serrated lesions associated with invasive carcinoma and high-grade intraepithelial neoplasm. Exp Ther Med 2013;6:1113-20.

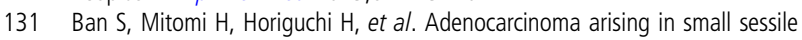
serrated adenoma/polyp (SSA/P) of the colon: clinicopathological study of eight lesions. Pathol Int 2014;64:123-32.

132 Goldstein NS. Small colonic microsatellite unstable adenocarcinomas and high-grade epithelial dysplasias in sessile serrated adenoma polypectomy specimens: a study of eight cases. Am J Clin Pathol 2006;125:132-45.

133 Nishihara R, Wu K, Lochhead $\mathrm{P}$, et al. Long-term colorectal-cancer incidence and mortality after lower endoscopy. N Engl I Med 2013;369:1095-105.

134 Biswas S, Ellis AJ, Guy R, et al. High prevalence of hyperplastic polyposis syndrome (serrated polyposis) in the NHS Bowel Cancer Screening Programme. Gut 2013:62:475.

135 Kahi CJ, Li X, Eckert GJ, et al. High colonoscopic prevalence of proximal colon serrated polyps in average-risk men and women. Gastrointest Endosc 2012;75:515-20.

136 Lockett M, Atkin WS. Hyperplastic polyposis: prevalence and cancer risk. Gut 2001;49(Suppl 1):A4 [abstract].

137 Moreira L, Pellisé M, Carballal S, et al. High prevalence of serrated polyposis syndrome in FIT-based colorectal cancer screening programmes. Gut 2013;62:476-7.

138 Orlowska J, Kiedrowski M, Kaminski MF. Hyperplastic polyposis syndrome in asymptomatic patients: the result from the colorectal-cancer screening program. Virchows Arch 2009;455(Suppl 1):S47.

139 Williams GT, Arthur JF, Bussey HJ, et al. Metaplastic polyps and polyposis of the colorectum. Histopathology 1980;4:155-70.

140 Boparai KS, Mathus-Vliegen EM, Koornstra JJ, et al. Increased colorectal cancer risk during follow-up in patients with hyperplastic polyposis syndrome: a multicentre cohort study. Gut 2010;59:1094-100.

141 Edelstein DL, Axilbund JE, Hylind LM, et al. Serrated polyposis: rapid and relentless development of colorectal neoplasia. Gut 2013;62:404-8.

142 IJspeert JE, Rana SA, Atkinson NS, et al. Clinical risk factors of colorectal cancer in patients with serrated polyposis syndrome: a multicentre cohort analysis. Gut 2017;66:278-84.
143 Carballal S, Rodríguez-Alcalde D, Moreira L, et al. Colorectal cancer risk factors in patients with serrated polyposis syndrome: a large multicentre study. Gut 2016;65:1829-37.

144 Boparai KS, Reitsma JB, Lemmens V, et al. Increased colorectal cancer risk in first-degree relatives of patients with hyperplastic polyposis syndrome. Gut 2010;59:1222-5.

145 Win AK, Walters RJ, Buchanan DD, et al. Cancer risks for relatives of patients with serrated polyposis. Am J Gastroenterol 2012;107:770-8.

146 Hazewinkel Y, Reitsma JB, Nagengast FM, et al. Extracolonic cancer risk in patients with serrated polyposis syndrome and their first-degree relatives. Fam Cancer 2013;12:669-73.

147 Cheah PY, Wong YH, Chau YP, et al. Germline bone morphogenesis protein receptor $1 \mathrm{~A}$ mutation causes colorectal tumorigenesis in hereditary mixed polyposis syndrome. Am J Gastroenterol 2009;104:3027-33.

148 Mongin C, Coulet F, Lefevre JH, et al. Unexplained polyposis: a challenge for geneticists, pathologists and gastroenterologists. Clin Genet 2012;81:38-46.

149 Heald B, Mester J, Rybicki L, et al. Frequent gastrointestinal polyps and colorectal adenocarcinomas in a prospective series of PTEN mutation carriers. Gastroenterology 2010;139:1927-33.

150 Sweet K, Willis J, Zhou XP, et al. Molecular classification of patients with unexplained hamartomatous and hyperplastic polyposis. JAMA 2005;294: 2465-73.

151 Jaeger $\mathrm{E}$, Leedham $\mathrm{S}$, Lewis $\mathrm{A}$, et al. Hereditary mixed polyposis syndrome is caused by a $40-\mathrm{kb}$ upstream duplication that leads to increased and ectopic expression of the BMP antagonist GREM1. Nat Genet 2012;44:699-703.

152 Gala MK, Mizukami Y, Le LP, et al. Germline mutations in oncogene-induced senescence pathways are associated with multiple sessile serrated adenomas. Gastroenterology 2014;146:520-9.

153 Clendenning M, Young JP, Walsh MD, et al. Germline mutations in the polyposis-associated genes BMPR1A, SMAD4, PTEN, MUTYH and GREM1 are not common in individuals with serrated polyposis syndrome. PLOS ONE 2013; 8:e66705.

154 Hazewinkel Y, Tytgat KM, van Eeden S, et al. Incidence of colonic neoplasia in patients with serrated polyposis syndrome who undergo annual endoscopic surveillance. Gastroenterology 2014;147:88-95.

155 Leonard DF, Dozois EJ, Smyrk TC, et al. Endoscopic and surgical management of serrated colonic polyps. Br J Surg 2011;98:1685-94.

156 Bossard C, Denis MG, Bézieau S, et al. Involvement of the serrated neoplasia pathway in inflammatory bowel disease-related colorectal oncogenesis. Oncol Rep 2007;18:1093-7.

157 Rubio CA. Serrated neoplasias and de novo carcinomas in ulcerative colitis: a histological study in colectomy specimens. I Gastroenterol Hepatol 2007;22:1024-31.

158 Rubio CA, Befrits R, Jaramillo $E$, et al. Villous and serrated adenomatous growth bordering carcinomas in inflammatory bowel disease. Anticancer Res 2000;20:4761-4.

159 Aust DE, Haase M, Dobryden L, et al. Mutations of the BRAF gene in ulcerative colitis-related colorectal carcinoma. Int I Cancer 2005;115:673-7.

160 Odze RD, Brien T, Brown CA, et al. Molecular alterations in chronic ulcerative colitis-associated and sporadic hyperplastic polyps: a comparative analysis. Am J Gastroenterol 2002;97:1235-42.

161 Srivastava A, Redston M, Farraye FA, et al. Hyperplastic/serrated polyposis in inflammatory bowel disease: a case series of a previously undescribed entity. $A m$ J Surg Pathol 2008;32:296-303.

162 Rex DK, Petrini JL, Baron TH, et al. Quality indicators for colonoscopy. Am J Gastroenterol 2006;101:873-85.

163 Anderson JC, Butterly LF, Goodrich M, et al. Differences in detection rates of adenomas and serrated polyps in screening versus surveillance colonoscopies, based on the New Hampshire colonoscopy registry. Clin Gastroenterol Hepatol 2013;11:1308-12.

164 Leung WK, Tang V, Lui PC. Detection rates of proximal or large serrated polyps in Chinese patients undergoing screening colonoscopy. J Dig Dis 2012;13: 466-71.

165 Liang J, Kalady MF, Appau K, et al. Serrated polyp detection rate during screening colonoscopy. Colorectal Dis 2012;14:1323-7.

166 Gurudu SR, Heigh RI, De Petris G, et al. Sessile serrated adenomas: demographic, endoscopic and pathological characteristics. World I Gastroenterol 2010;16:3402-5.

167 Kumbhari V, Behary J, Hui JM. Prevalence of adenomas and sessile serrated adenomas in Chinese compared with Caucasians. I Gastroenterol Hepatol 2013;28:608-12.

168 Rex DK, Bond JH, Winawer S, et al. Quality in the technical performance of colonoscopy and the continuous quality improvement process for colonoscopy: recommendations of the U.S. Multi-Society Task Force on Colorectal Cancer. Am J Gastroenterol 2002:97:1296-308.

169 IJspeert JE, van Doorn SC, van der Brug YM, et al. The proximal serrated polyp detection rate is an easy-to-measure proxy for the detection rate of clinically relevant serrated polyps. Gastrointest Endosc 2015;82:870-7. 